\title{
Photoelectron Spectroscopic Study of the Oxyallyl Diradical
}

Takatoshi Ichino, ${ }^{+, \neq}$Stephanie M. Villano, ${ }^{+, \perp}$ Adam J. Gianola, ${ }^{\dagger}$ Daniel J. Goebbert, ${ }^{\S, \nabla}$ Luis Velarde, ${ }^{\S, \bigcirc}$ Andrei Sanov, ${ }^{\S}$ Stephen J. Blanksby," Xin Zhou, " David A. Hrovat, ${ }^{\#}$ Weston Thatcher Borden, ${ }^{\#}$ and W. Carl Lineberger ${ }^{*,+}$

${ }^{\dagger} \mathrm{JILA}$,University of Colorado and National Institute of Standards and Technology, and Department of Chemistry and Biochemistry, University of Colorado, Boulder, Colorado 80309-0440, United States

${ }^{\ddagger}$ Department of Chemistry and Biochemistry, The University of Texas at Austin, Austin, Texas 78712-0165, United States

${ }^{\S}$ Department of Chemistry and Biochemistry, University of Arizona, Tucson, Arizona 85721-0041, United States

"School of Chemistry, University of Wollongong, Wollongong, NSW 2522, Australia

${ }^{*}$ Department of Chemistry and Center for Advanced Scientific Computing and Modeling, University of North Texas, Denton, Texas 76203-5070, United States

Supporting Information

ABSTRACT: The photoelectron spectrum of the oxyallyl (OXA) radical anion has been measured. The radical anion has been generated in the reaction of the atomic oxygen radical anion $\left(\mathrm{O}^{\bullet-}\right)$ with acetone. Three low-lying electronic states of OXA have been observed in the spectrum. Electronic structure calculations have been performed for the triplet states $\left({ }^{3} \mathrm{~B}_{2}\right.$ and $\left.{ }^{3} \mathrm{~B}_{1}\right)$ of OXA and the ground doublet state $\left({ }^{2} \mathrm{~A}_{2}\right)$ of the radical anion using density functional theory (DFT). Spectral simulations have been carried out for the triplet states based on the results of the DFT calculations. The simulation identifies a vibrational progression of the CCC bending mode of the ${ }^{3} \mathrm{~B}_{2}$ state of OXA in the lower electron binding energy ( $\mathrm{eBE}$ ) portion of the spectrum. On top of the ${ }^{3} \mathrm{~B}_{2}$ feature, however, the experimental spectrum exhibits additional photoelectron peaks whose angular distribution is distinct from that for the vibronic peaks of the ${ }^{3} \mathrm{~B}_{2}$ state. Complete active space selfconsistent field (CASSCF) method and second-order perturbation

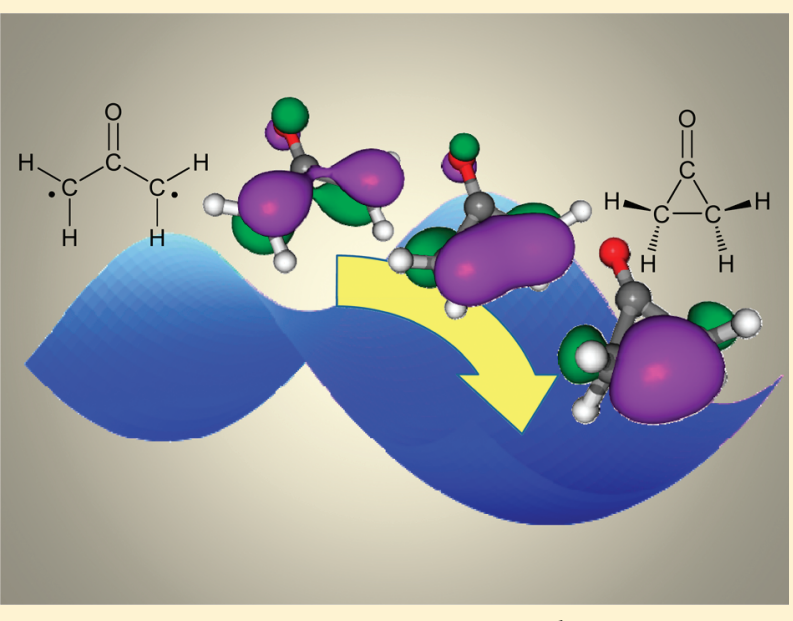
theory based on the CASSCF wave function (CASPT2) have been employed to study the lowest singlet state $\left({ }^{1} \mathrm{~A}_{1}\right)$ of OXA. The simulation based on the results of these electronic structure calculations establishes that the overlapping peaks represent the vibrational ground level of the ${ }^{1} \mathrm{~A}_{1}$ state and its vibrational progression of the $\mathrm{CO}$ stretching mode. The ${ }^{1} \mathrm{~A}_{1}$ state is the lowest electronic state of OXA, and the electron affinity (EA) of OXA is $1.940 \pm 0.010 \mathrm{eV}$. The ${ }^{3} \mathrm{~B}_{2}$ state is the first excited state with an electronic term energy of $55 \pm 2 \mathrm{meV}$. The widths of the vibronic peaks of the $\tilde{X}^{1} \mathrm{~A}_{1}$ state are much broader than those of the $\tilde{a}^{3} \mathrm{~B}_{2}$ state, implying that the ${ }^{1} \mathrm{~A}_{1}$ state is indeed a transition state. The CASSCF and CASPT2 calculations suggest that the ${ }^{1} \mathrm{~A}_{1}$ state is at a potential maximum along the nuclear coordinate representing disrotatory motion of the two methylene groups, which leads to three-membered-ring formation, i.e., cyclopropanone. The simulation of $\tilde{b}^{3} \mathrm{~B}_{1}$ OXA reproduces the higher eBE portion of the spectrum very well. The term energy of the ${ }^{3} \mathrm{~B}_{1}$ state is $0.883 \pm 0.012 \mathrm{eV}$. Photoelectron spectroscopic measurements have also been conducted for the other ion products of the $\mathrm{O}^{--}$reaction with acetone. The photoelectron imaging spectrum of the acetylcarbene (AC) radical anion exhibits a broad, structureless feature, which is assigned to the $\tilde{\mathrm{X}}^{3} \mathrm{~A}^{\prime \prime}$ state of AC. The ground $\left({ }^{2} \mathrm{~A}^{\prime \prime}\right)$ and first excited $\left({ }^{2} \mathrm{~A}^{\prime}\right)$ states of the 1-methylvinoxy (1-MVO) radical have been observed in the photoelectron spectrum of the 1-MVO ion, and their vibronic structure has been analyzed.

\section{INTRODUCTION}

A class of molecules known as non-Kekulé hydrocarbons ${ }^{1}$ are diradicals, ${ }^{2-5}$ in which two (nearly) degenerate, nonbonding molecular orbitals (MOs) are occupied by two electrons. Their unique electronic structures have been the subject of many theoretical and experimental investigations. Trimethylene- methane (TMM) is the simplest non-Kekule hydrocarbon (see Figure 1). Following early theoretical studies, ${ }^{6,7}$ pioneering ESR

Received: November 29, 2010

Revised: January 14, 2011

Published: February 16, 2011 
<smiles>C=C=C</smiles>

$A C$<smiles>CC(=O)C=O</smiles>

syn-staggered<smiles>COC=CC=O</smiles><smiles>[1H]C([18O])C(=O)C=CC</smiles><smiles>O=C1CC1</smiles>

Cyclopropanone<smiles>C=CC(C)=O</smiles>

syn-eclipsed<smiles>C=CC=O</smiles><smiles>C=CC=O</smiles>

anti-staggered<smiles>C=CC=O</smiles>

anti-eclipsed

Figure 1. Molecules discussed in the present work.

measurements by Dowd and co-workers ${ }^{7-9}$ established that the electronic ground state of TMM is triplet $\left({ }^{3} \mathrm{~A}_{2}{ }^{\prime}\right)$, which is in accord with Hund's rule for a case of a nondisjoint degenerate pair of nonbonding MOs. ${ }^{3,410,11}$ Also, the IR spectrum of TMM was obtained by Maier and co-workers ${ }^{12}$ in a halogen-doped xenon matrix. Subsequently, Lineberger and co-workers measured the photoelectron spectrum of the TMM radical anion, which revealed the vibronic structure of not only the ground triplet state but also an excited singlet state $\left({ }^{1} \mathrm{~A}_{1}\right)$ of TMM. ${ }^{13,14}$ This photoelectron spectroscopic study determined the energy gap between the two states. These experimental findings have been compared with results of theoretical studies using advanced electronic structure methods. ${ }^{3,11,15-20}$

Substitution effects on the electronic structure of TMM have gained considerable interest over the years. In particular, substitution of a methylene group in TMM for an $\mathrm{O}$ atom results in oxyallyl (OXA; see Figure 1). OXA has been regarded as an intermediate or a transition state for the ring opening of cyclopropanones ${ }^{21-24}$ and allene oxides, ${ }^{24,25}$ the Favorskii rearrangements, ${ }^{26}$ and other synthetically useful transformations. ${ }^{27} \mathrm{~A}$ number of theoretical accounts of the electronic structure of OXA have been presented in the literature, ${ }^{28-31}$ but no direct spectroscopic observations of OXA had been reported until its recent detection through photodetachment of the radical anion of OXA. ${ }^{32,33}$ These experimental results have also prompted an extensive theoretical study of the electronic structure of OXA using a high-level ab initio method, i.e., equation-of-motion coupled-cluster theory (EOM-CC). ${ }^{33}$ The present paper follows up the preliminary report ${ }^{32}$ with a detailed description of the experimental findings and analysis of the photoelectron spectrum of the OXA radical anion.

Synthesis of the negative ion of TMM has been developed by Squires and co-workers, ${ }^{34}$ making use of fluorine ion chemistry with a trimethylsilyl derivative. Although the same approach can be adopted for the synthesis of the OXA radical anion, ${ }^{35}$ there is an alternative, simpler method to generate the anion at the expense of reaction selectivity. The atomic oxygen radical anion $\left(\mathrm{O}^{\bullet-}\right)$ abstracts $\mathrm{H}_{2}{ }^{-+}$from acetone to form the OXA radical anion (reaction 1), ${ }^{36,37}$ whose mass/charge ratio $(\mathrm{m} / \mathrm{e})$ is 56 . The reaction of $\mathrm{O}^{\circ-}$ with acetone also yields other product ions including a structural isomer, the radical anion of acetylcarbene
(AC) (reaction 2), ${ }^{38}$ and the 1-methylvinoxide (1-MVO) ion (reaction 3). ${ }^{36,37,39}$

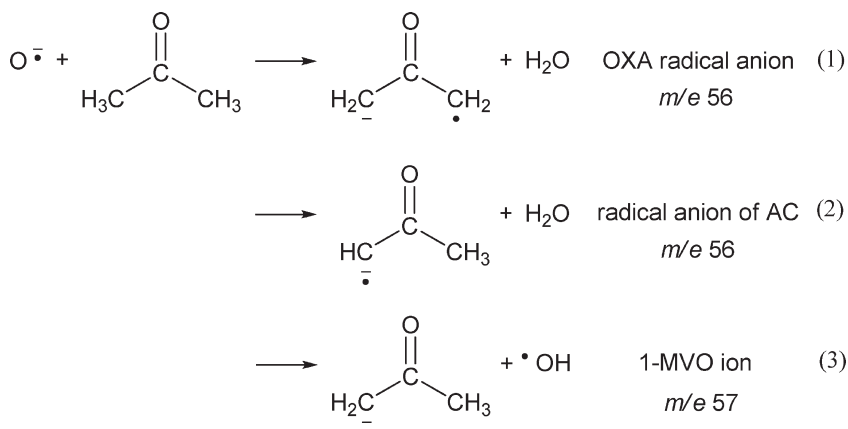

In this article, the photoelectron spectra of the ion products of the reaction of $\mathrm{O}^{\bullet-}$ with acetone are presented. Analyses of the spectra are facilitated by electronic structure calculations using the density functional theory (DFT) and complete active space self-consistent field (CASSCF) method and its associated second-order perturbation theory (CASPT2). It is shown that these theoretical methods, albeit not as sophisticated as that employed in ref 33, are capable of faithful interpretation of the complicated OXA spectra. The vibronic structures of OXA, AC, and the 1-MVO radical are discussed.

\section{EXPERIMENTAL AND THEORETICAL METHODS}

2.1. Photoelectron Spectroscopy with a Flowing Afterglow lon Source. Ultraviolet photoelectron spectroscopic measurements for ions generated in a flowing afterglow negative ion source have been performed with an experimental system described elsewhere. ${ }^{40-42}$ A microwave discharge of helium buffer gas $(\sim 0.4$ Torr $)$ containing a small amount of $\mathrm{O}_{2}$ produces $\mathrm{O}^{\bullet-}$. The reaction of $\mathrm{O}^{\bullet-}$ with acetone (Aldrich) introduced downstream in the flow tube yields the OXA radical anion $(\mathrm{m} / \mathrm{e}$ 56 , reaction 1$)$, the AC radical anion $(\mathrm{m} / \mathrm{e} 56$, reaction 2$)$, and the 1-MVO ion $(m / e ~ 57$, reaction 3$)$ as major product ions. ${ }^{36-39}$ In separate measurements, a trace amount of methane is introduced before acetone to quantitatively convert $\mathrm{O}^{\bullet-}$ to the hydroxide ion $\left(\mathrm{HO}^{-}\right)$. The reaction of $\mathrm{HO}^{-}$with acetone 
produces the 1-MVO ion (reaction 4), but no $m / e 56$ ions are generated in this case.

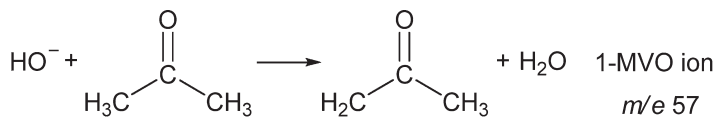

The ions are thermalized through collisions with helium buffer gas in the flow tube at room temperature. In some measurements, the flow tube is cooled with a flow of liquid nitrogen, and the ion temperature is typically lowered to $\leq 200 \mathrm{~K}$. The negative ions are extracted into a differentially pumped region, accelerated to $740 \mathrm{eV}$, and focused into a Wien velocity filter for mass selection. The mass-selected ions are refocused and decelerated to $35 \mathrm{eV}$ into an interaction region where the ion beam is overlapped with a laser beam in a high-vacuum build-up cavity for photodetachment. The output of a continuous wave argon ion laser (351.1 $\mathrm{nm}, 3.531 \mathrm{eV}$ ) is amplified in the cavity with a circulating power of $\sim 100 \mathrm{~W}$. A typical beam current for the $m / e 56$ ions is $200 \mathrm{pA}$ at room temperature.

Photodetached electrons emitted into a small solid angle perpendicular to both the ion and laser beams are focused into a hemispherical kinetic energy analyzer with a resolution of 8-10 $\mathrm{meV}$. The energy-analyzed electrons are magnified onto the microchannel plates (MCPs) and imaged onto the position sensitive detector. The analyzer setting is controlled to scan the photoelectrons with different kinetic energies and construct spectra. The electron kinetic energy ( $\mathrm{eKE}$ ) is converted to the electron binding energy ( $\mathrm{eBE}$ ) by subtracting eKE from the laser photon energy. The absolute kinetic energy is calibrated in the measurements of the photoelectron spectrum of $\mathrm{O}^{\bullet-}$ against the very accurately known electron affinity (EA) of the $\mathrm{O}$ atom. ${ }^{43}$ To calibrate the energy scale, a small $(<1 \%)$ compression factor ${ }^{42}$ of the energy analyzer is determined in the measurements of the photoelectron spectrum of the tungsten anion with reference to the electronic term energies of the tungsten atom. ${ }^{44}$ A rotatable half-wave plate controls the direction of the electric field vector of the laser beam. The differential cross section for photodetachment is expressed as follows: ${ }^{45}$

$$
\frac{\mathrm{d} \sigma}{\mathrm{d} \Omega}=\frac{\sigma_{0}}{4 \pi}\left(1+\beta P_{2}(\cos \theta)\right)
$$

Here, $\sigma_{0}$ and $\beta$ are the total cross section and anisotropy parameter, respectively. Note that these are functions of the electron kinetic energy. Also, $P_{2}(\cos \theta)$ is the second Legendre polynomial, where $\theta$ is the angle between the laser beam polarization vector and the photoelectron momentum vector. The $\beta$ values are determined from measurements of photoelectron count rates as a function of $\theta$. The measurements at the magic angle, i.e., $\theta=$ $54.7^{\circ}$, provide photoelectron intensities uniformly proportional to $\sigma_{0}$ at all kinetic energies.

2.2. Photoelectron Imaging Spectroscopy with a Pulsed Ion Source. Details of a pulsed time-of-flight photofragmentation-photoelectron imaging spectrometer have been given in the literature. ${ }^{46}$ Ions are generated via ion-molecule reactions in a pulsed molecular beam. The gas mixture, which consists of neat $\mathrm{N}_{2} \mathrm{O}$ with acetone vapor with a backing pressure of $20 \mathrm{psi}$, is expanded into the vacuum chamber. High energy electron collisions $(\sim 1 \mathrm{keV})$ produce cations and slow secondary electrons which dissociatively attach to $\mathrm{N}_{2} \mathrm{O}$ to form $\mathrm{O}^{\bullet-}$. The $\mathrm{O}^{\bullet-}$ ion subsequently reacts with acetone to produce molecular anions as shown in reactions $1-3$. An isotopologue, 1,1, 1-trideuteroacetone (Aldrich, 99 atom \% D), is also used as a reactant to generate isotopologues of the ion products. The negative ions are pulsed into a $2 \mathrm{~m}$ flight tube, where they separate by mass, and are detected using an MCP. Approximately $30 \mathrm{~cm}$ before the detector is a laser interaction region equipped with a velocity-map ${ }^{47}$ imaging $^{48}$ apparatus. Here, a linearly polarized (along the ion beam direction) beam of the second $(532 \mathrm{~nm})$ or third $(355 \mathrm{~nm})$ harmonic of a pulsed Nd:YAG laser (pulse duration of $\sim 8 \mathrm{~ns}$ at $50 \mathrm{~Hz}$, maximum power 60 and $25 \mathrm{~mJ} /$ pulse for 532 and $355 \mathrm{~nm}$ light, respectively) intersects the ion beam at right angles. Photodetached electrons are extracted from the region with an electric field perpendicular to the ion and laser beams and focused onto an imaging MCP coupled to a P43 phosphor screen. Images are acquired using a CCD camera. Each image is composed of $(0.5-1) \times 10^{5}$ frames. The images are transformed using the BASEX program, ${ }^{49}$ and the calibration of the energy scale is performed using the EA of the $\mathrm{O}$ atom. ${ }^{43}$

2.3. Electronic Structure Calculations. A variant of DFT, (U)B3LYP, ${ }^{50}$ and the CASSCF method $^{51}$ were employed to study the electronic structures of the molecules. The CAS consists of all configurations that result from placing either four (for OXA) or five (for the OXA radical anion) electrons in the four $\pi$ MOs, i.e., (4/4)CASSCF or (5/4)CASSCF. The effects of dynamic electron correlation ${ }^{52}$ were explored with CASPT2 calculations $^{53}$ at each CASSCF stationary point. The $6-311++\mathrm{G}-$ $(\mathrm{d}, \mathrm{p}),{ }^{54} \mathrm{cc}-\mathrm{pVTZ},{ }^{55}$ and aug-cc-pVTZ basis sets ${ }^{56}$ were used for these calculations. The DFT calculations were performed with the Gaussian 03 program suite, ${ }^{57}$ and the CASSCF calculations were carried out with the MOLCAS program system. ${ }^{58}$ Readers are also referred to ref 33, where the results of EOM-CC calculations of OXA are presented.

\section{RESULTS}

3.1. Photoelectron Spectrum of the Oxyallyl Radical Anion. The photoelectron spectra of negative ions generated from the reaction of $\mathrm{O}^{--}$with acetone in the flowing afterglow ion source are displayed in Figure 2a. The Wien velocity filter was adjusted to mainly transmit the $m / e 56$ product ions (reactions 1 and 2), but some $\mathrm{m} / \mathrm{e} 57$ product ions (reaction 3 ) passed through the filter owing to its limited mass resolution. As will be shown in section 3.3, the peaks marked with asterisks are due to detachment from the 1-MVO ion. In order to focus on the $m / e$ 56 product ions, photoelectron contributions from the 1-MVO ion (see section 3.3) were subtracted from the spectra in Figure $2 \mathrm{a}$, and the resultant spectra are shown in Figure $2 \mathrm{~b}$.

The lower eBE portion of the subtracted spectra is expanded in Figure 3a, where five peaks are prominent. Among these peaks, peak $\mathrm{A}$ has a distinct angular dependence (see eq 5): its intensity is comparable to those of the other peaks when $\theta=90^{\circ}$, but its relative intensity is quite diminished when $\theta=0^{\circ}$. Thus, the $\beta$ value of peak $A,-0.80 \pm 0.05$, is more negative than those of the other peaks (e.g., $-0.60 \pm 0.05$ for peak B). Furthermore, the width of peak $A$ is much broader than those of peaks $B, C$, and D. These observations suggest that more than one electronic state of OXA and/or AC appears in the spectra shown in Figure 3a. The observed peak positions are listed in Table 1.

It has been reported that quantum chemical calculations predict that the lowest singlet $\left({ }^{1} \mathrm{~A}_{1}\right)$ and triplet $\left({ }^{3} \mathrm{~B}_{2}\right)$ states of OXA are nearly degenerate. ${ }^{29,33}$ The possibility that these states 


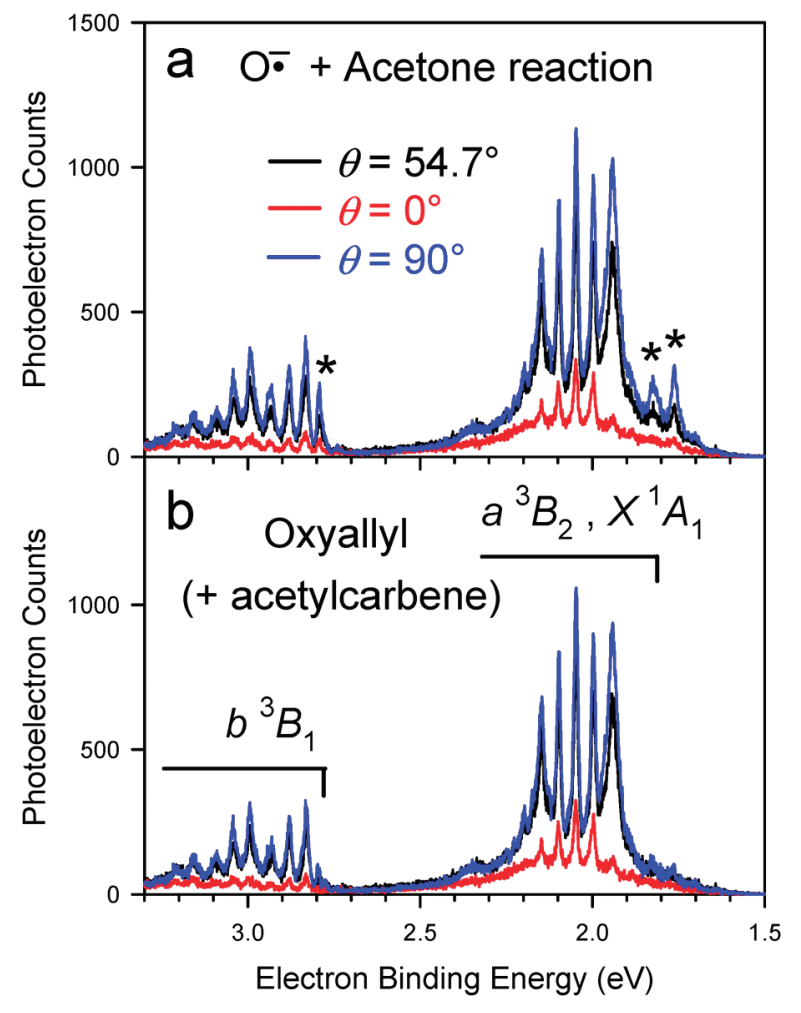

Figure 2. (a) Photoelectron spectra of the ions $(\mathrm{m} / \mathrm{e} 56$ and 57) produced from the reaction of $\mathrm{O}^{--}$with acetone (reactions $1-3$ ) in the flowing afterglow ion source at room temperature. The spectra were taken at $\theta=54.7^{\circ}$ (black), $0^{\circ}$ (red), and $90^{\circ}$ (blue). The photoelectron peaks marked with asterisks originate from the 1-MVO ion. (b) Contributions of photoelectrons detached from the 1-MVO ion are subtracted from the photoelectron spectra shown in (a). These spectra represent mainly detachment from the OXA radical anion, but significant contributions from the $\mathrm{AC}$ radical anion are also present.

manifest themselves in the spectra in Figure $3 \mathrm{a}$ is examined. First, the ${ }^{3} \mathrm{~B}_{2}$ state is considered. The $C_{2 v}$ equilibrium geometry of the ${ }^{3} \mathrm{~B}_{2}$ state of OXA was calculated with the B3LYP/6-311++ $\mathrm{G}(\mathrm{d}, \mathrm{p})$ method, and the geometric parameters so obtained are given in Table 2 . Table 2 also displays the similarly calculated geometric parameters for the electronic ground state $\left({ }^{2} \mathrm{~A}_{2}\right)$ of the OXA radical anion. Harmonic vibrational analyses were conducted for these states, and the results are given in Table S1 of the Supporting Information. Both states have potential minima at the corresponding $C_{2 v}$ equilibrium geometries.

The DFT calculations predict the eBE of the OXA radical anion relative to the ${ }^{3} \mathrm{~B}_{2}$ state of OXA to be $1.979 \mathrm{eV} .{ }^{59}$ This calculated energetics supports the notion that the major peaks in Figure $3 \mathrm{a}$ represent the vibronic levels of the ${ }^{3} \mathrm{~B}_{2}$ state. The PESCAL program ${ }^{60}$ was employed to carry out spectral simulations based on the results of the geometry optimizations and the harmonic vibrational analysis of the DFT calculations. Figure $3 \mathrm{~b}$ shows the simulated spectrum superimposed on the experimental spectrum taken at $\theta=0^{\circ}$, where peak $A$ is relatively suppressed because of its angular dependence. The position of the origin peak of the simulated spectrum was set to that of peak $B$. The relative intensities and energy separations of peaks $B, C, D$, and $E$ are well reproduced in the simulation. Thus, peak $\mathrm{B}$ is assigned to be the vibrational ground level of the ${ }^{3} B_{2}$ state, and peaks $C, D$, and $\mathrm{E}$ represent the fundamental and the first and second overtone levels of the $v_{7}$ mode (CCC bending), respectively.

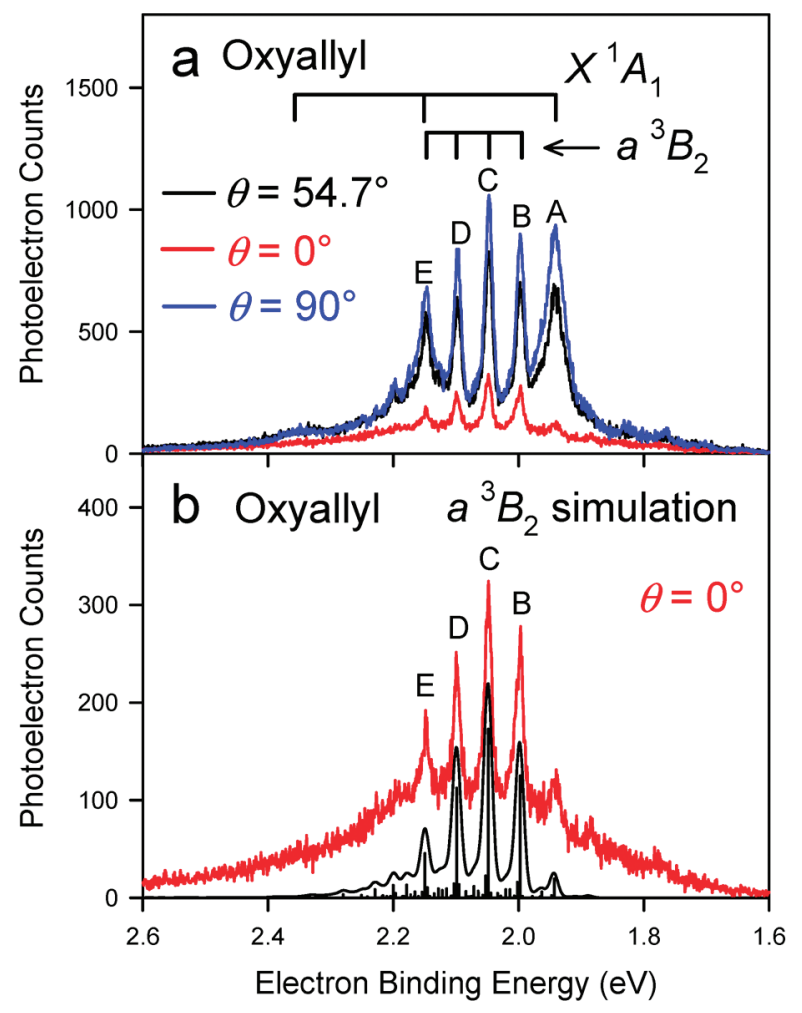

Figure 3. (a) Expansion of the lower eBE portion of the spectra shown in Figure 2b. (b) A simulation of the photoelectron spectrum of the OXA radical anion (black line) that corresponds to detachment to $\tilde{a}^{3} \mathrm{~B}_{2}$ OXA is superimposed on the experimental $\theta=0^{\circ}$ spectrum from (a) (red line). Simulated individual vibronic transitions (sticks) are convoluted with a Gaussian function of a fwhm of $15 \mathrm{meV}$. The vibrational temperature of the ion was assumed to be $298 \mathrm{~K}$ in the simulation.

Table 1. Peak Positions and Assignments of the Photoelectron Spectrum of Oxyallyl Radical Anion

\begin{tabular}{cccl} 
oxyallyl & peak $^{a}$ & peak position $^{b}\left(\mathrm{~cm}^{-1}\right)$ & \multicolumn{1}{c}{ assignment $^{c}$} \\
$\tilde{\mathrm{X}}^{1} \mathrm{~A}_{1}$ & $\mathrm{~A}$ & 0 & $0_{0}^{0}(\mathrm{EA}=1.940 \pm 0.010 \mathrm{eV})$ \\
$\tilde{\mathrm{a}}^{3} \mathrm{~B}_{2}$ & $\mathrm{~B}$ & 0 & $0_{0}^{0}\left(T_{0}=0.055 \pm 0.002 \mathrm{eV}\right)$ \\
& $\mathrm{C}$ & $405 \pm 10$ & $7_{0}^{1}$ \\
& $\mathrm{D}$ & $805 \pm 15$ & $7_{0}^{2}$ \\
& $\mathrm{E}$ & $1210 \pm 20$ & $7_{0}^{3}$ \\
$\tilde{\mathrm{b}}^{3} \mathrm{~B}_{1}$ & $\mathrm{~A}$ & 0 & $0_{0}^{0}\left(T_{0}=0.883 \pm 0.012 \mathrm{eV}\right)$ \\
& $\mathrm{B}$ & $400 \pm 20$ & $7_{0}^{1}$ \\
& $\mathrm{C}$ & $815 \pm 25$ & $7_{0}^{2}$ \\
& $\mathrm{D}$ & $1315 \pm 35$ & $4_{0}^{1}$ \\
& $\mathrm{E}$ & $1700 \pm 30$ & $4_{0}^{1} 7_{0}^{1}$ \\
& $\mathrm{~F}$ & $2095 \pm 45$ & $4_{0}^{1} 7_{0}^{2}$ \\
& $\mathrm{G}$ & $2625 \pm 50$ & $4_{0}^{2}$ \\
$\mathrm{H}$ & $3010 \pm 50$ & $4_{0}^{2} 7_{0}^{1}$
\end{tabular}

${ }^{a}$ The peak labels are shown in Figures $3-5 .{ }^{b}$ The peak positions are given relative to the vibrational ground level of the corresponding electronic state. ${ }^{c}$ See the text for descriptions of the normal modes. EA, electron affinity; $T_{0}$, electronic term energy.

This observation of the vibrational progression reflects significant nuclear displacements from the equilibrium geometry of the ${ }^{2} \mathrm{~A}_{2}$ state of the radical anion to that of the ${ }^{3} \mathrm{~B}_{2}$ state of OXA along the CCC bending coordinate (Table 2). The simulation also 
Table 2. Calculated Equilibrium Geometry Parameters of Oxyallyl and Oxyallyl Radical Anion ${ }^{a}$

\begin{tabular}{|c|c|c|c|c|c|c|}
\hline & \multirow{2}{*}{\multicolumn{2}{|c|}{$\frac{\text { oxyallyl radical anion }}{\tilde{\mathrm{X}}^{2} \mathrm{~A}_{2}}$}} & \multicolumn{4}{|c|}{ oxyallyl } \\
\hline & & & \multirow{2}{*}{$\frac{\tilde{\mathrm{X}}^{1} \mathrm{~A}_{1}}{\mathrm{CASSCF}}$} & \multicolumn{2}{|c|}{$\tilde{\mathrm{a}}^{3} \mathrm{~B}_{2}$} & \multirow{2}{*}{$\frac{\tilde{\mathrm{b}}^{3} \mathrm{~B}_{1}}{\mathrm{DFT}}$} \\
\hline & DFT & CASSCF & & DFT & CASSCF & \\
\hline $\mathrm{CO}$ & 1.2761 & 1.2627 & 1.2062 & 1.2682 & 1.2413 & 1.3356 \\
\hline $\mathrm{CC}$ & 1.4345 & 1.4240 & 1.4620 & 1.4353 & 1.4395 & 1.3936 \\
\hline $\mathrm{CH}_{\alpha}$ & 1.0858 & 1.0757 & 1.0713 & 1.0817 & 1.0700 & 1.0804 \\
\hline $\mathrm{CH}_{\beta}$ & 1.0858 & 1.0753 & 1.0700 & 1.0833 & 1.0708 & 1.0805 \\
\hline OCC & 122.78 & 122.84 & 123.19 & 119.05 & 119.36 & 118.01 \\
\hline $\mathrm{CCC}$ & 114.44 & 114.32 & 113.63 & 121.89 & 121.28 & 123.97 \\
\hline $\mathrm{CCH}_{\alpha}$ & 119.87 & 120.09 & 119.43 & 118.55 & 118.78 & 121.78 \\
\hline $\mathrm{CCH}_{\beta}$ & 121.60 & 121.67 & 121.20 & 122.14 & 121.72 & 118.53 \\
\hline
\end{tabular}

${ }^{a}$ Bond lengths are in units of angstroms and bond angles are in units of degrees. See Figure 1 for the drawings of the molecular structure. DFT denotes B3LYP/6-311++G(d,p) calculations, and CASSCF means (4/4) and (5/4)CASSCF calculations for oxyallyl and the oxyallyl radical anion, respectively, with the cc-pVTZ basis set.

predicts a hot band of moderate intensity. This transition originates from the fundamental level of the CCC bending mode of the OXA radical anion to the vibrational ground level of the ${ }^{3} \mathrm{~B}_{2}$ state. It should be noted that the observed spectrum shown in Figure $3 \mathrm{~b}$ exhibits broad background photoelectron signals over the entire energy range. These photoelectrons are detached from the $\mathrm{AC}$ radical anion, which will be elaborated on in section 3.2.

The ${ }^{1} \mathrm{~A}_{1}$ state is studied next. Since its wave function has an appreciable multireference character, ${ }^{28,29}$ application of the B3LYP method to the ${ }^{1} A_{1}$ state of OXA seems unsuitable. ${ }^{19,35}$ Instead, the equilibrium geometries of the ${ }^{1} \mathrm{~A}_{1}$ and ${ }^{3} \mathrm{~B}_{2}$ states were calculated with the (4/4)CASSCF/cc-pVTZ method. The geometric parameters so obtained are displayed in Table 2 . Harmonic vibrational analyses were performed for the two states at the corresponding equilibrium geometries, and the results can be found in Table S1 in the Supporting Information. The CASPT2 energies were calculated at the CASSCF-optimized geometries, i.e., (4/4)CASPT2/aug-cc-pVTZ//(4/4)CASSCF/ cc-pVTZ, to account for dynamic electron correlation. These calculations predict that the ${ }^{1} \mathrm{~A}_{1}$ state lies below the ${ }^{3} \mathrm{~B}_{2}$ state in adiabatic energy by $40 \mathrm{meV} .^{61}$ This near degeneracy together with the aforementioned distinct angular dependences indicates that peak $A$ represents the vibrational ground level of the ${ }^{1} \mathrm{~A}_{1}$ state of OXA.

The vibrational feature observed in the spectrum also corroborates this assignment. (5/4)CASSCF/cc-pVTZ calculations were performed for the ${ }^{2} \mathrm{~A}_{2}$ state of the OXA radical anion, and the parameters of the optimized geometry are given in Table 2 . The ${ }^{1} \mathrm{~A}_{1}$ OXA spectrum was simulated using the equilibrium geometries and normal modes obtained with the CASSCF calculations. ${ }^{62}$ This ${ }^{1} \mathrm{~A}_{1}$ simulation and the ${ }^{3} \mathrm{~B}_{2}$ simulation described earlier in this section are compared with the magicangle spectrum of the OXA radical anion produced in the cooled flow tube (Figure 4). ${ }^{63}$ As in Figure 3b, the vibrational origin of the ${ }^{3} \mathrm{~B}_{2}$ simulation was set to peak $\mathrm{B}$, while that of the ${ }^{1} \mathrm{~A}_{1}$ simulation was set to peak A in Figure 4. Note that different full width at half-maximum (fwhm) values were used for the simulations: $11 \mathrm{meV}$ for ${ }^{3} \mathrm{~B}_{2}$ and $35 \mathrm{meV}$ for ${ }^{1} \mathrm{~A}_{1}$.

CASSCF calculations predict that the $\mathrm{CO}$ bond shortens by $0.0565 \AA$ upon photodetachment from the OXA radical anion to

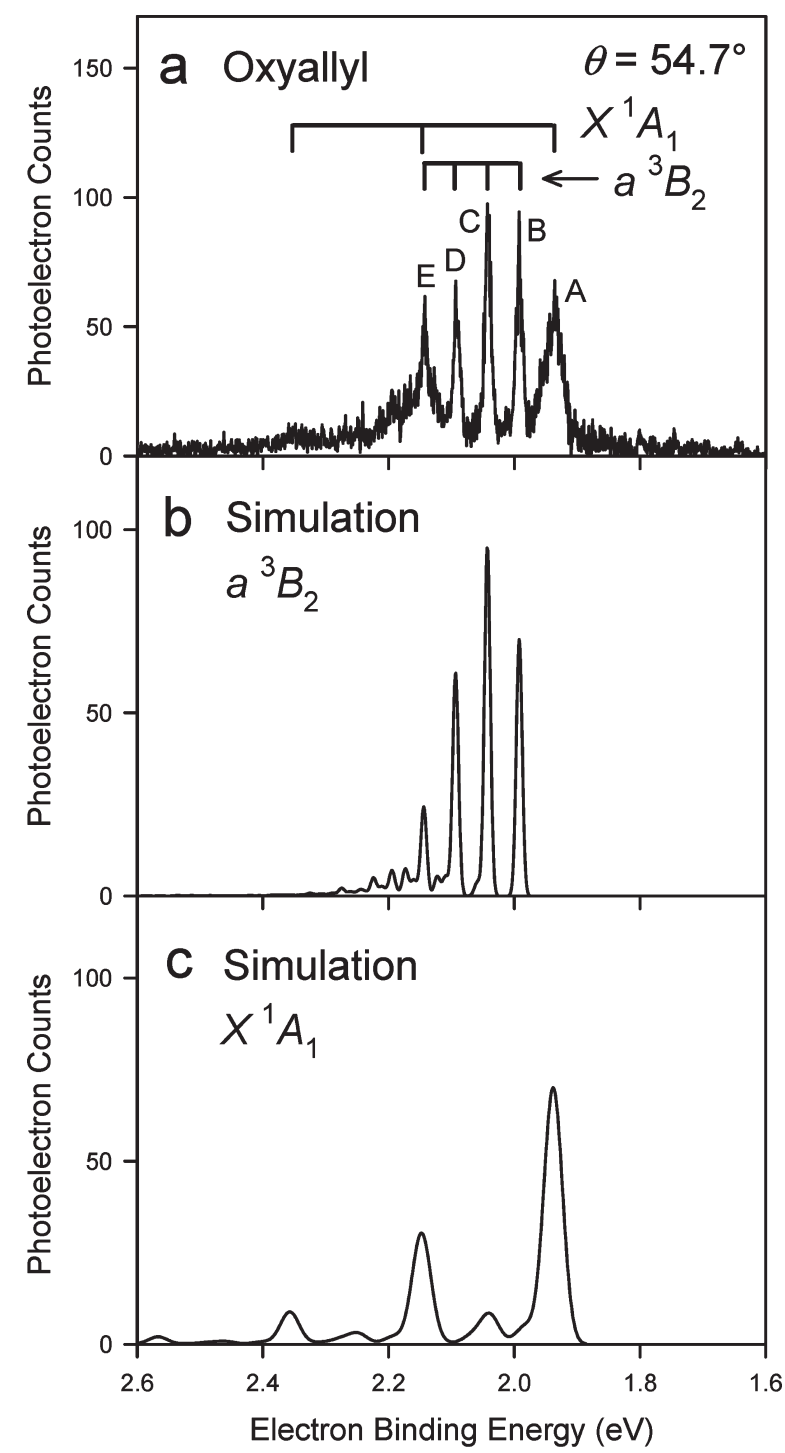

Figure 4. (a) Magic-angle photoelectron spectrum of the OXA radical anion generated in the flowing afterglow ion source where the flow tube was cooled with a flow of liquid nitrogen. (b) Simulation of the $\tilde{a}^{3} \mathrm{~B}_{2}$ OXA spectrum with a fwhm of $11 \mathrm{meV}$. (c) Simulation of the $\tilde{X}^{1} A_{1}$ OXA spectrum with a fwhm of $35 \mathrm{meV}$. The vibrational temperature of the ion was assumed to be $0 \mathrm{~K}$ in these simulations.

the ${ }^{1} \mathrm{~A}_{1}$ state of OXA. Consequently, as shown in Figure 4c, the ${ }^{1} \mathrm{~A}_{1}$ simulation anticipates a vibrational progression of the $\mathrm{CO}$ stretching mode $\left(v_{3}\right) .{ }^{64}$ Indeed, the magic-angle spectrum in Figure 4a shows a quite broad band at the base of relatively sharp peak $\mathrm{E}$. The broadness of this band is similar to that of peak A. The overlap with the second overtone peak of the $v_{7}$ mode of the ${ }^{3} \mathrm{~B}_{2}$ state makes it difficult to locate the center of the broad peak, but it is about $1680 \pm 50 \mathrm{~cm}^{-1}$ separated from peak A. It is reasonable that this interval represents the fundamental vibrational frequency of the $v_{3}$ mode of the ${ }^{1} \mathrm{~A}_{1}$ state of OXA in light of the CO bond shortening; B3LYP/6-311++G(d,p) calculations predict a harmonic frequency of $1512 \mathrm{~cm}^{-1}$ for the $v_{3}$ mode of the OXA radical anion (see Table S1 in the Supporting Information). Also, a weak broad band observed at $\mathrm{eBE} \sim 2.35 \mathrm{eV}$ most probably represents the overtone peak of the $v_{3}$ mode of the ${ }^{1} \mathrm{~A}_{1}$ state. Thus, the simulations shown in Figure $4 \mathrm{~b}, \mathrm{c}$ strongly suggest that the observed spectrum (Figure 4a) is a composite of 
the ${ }^{1} A_{1}$ and ${ }^{3} B_{2}$ spectra. Peak $A$ is assigned to be the vibrational ground level of the ${ }^{1} A_{1}$ state of OXA, and the EA of OXA is determined to be $1.940 \pm 0.010 \mathrm{eV}$ with the ${ }^{1} \mathrm{~A}_{1}$ state as its lowest electronic state. ${ }^{65}$ The electronic term energy of the ${ }^{3} \mathrm{~B}_{2}$ state is $55 \pm 2 \mathrm{meV}$. The present assignments match the results of recent EOM-CC calculations very well. ${ }^{33}$ In particular, the EOM-CC calculations predict the adiabatic energy separation between the ${ }^{1} \mathrm{~A}_{1}$ and ${ }^{3} \mathrm{~B}_{2}$ states to be $63 \mathrm{meV}$ when the singles and doubles approximation of the $\mathrm{CC}$ theory is supplemented with noniterative triples correction, i.e., EOM-CCSD $(\mathrm{dT})$.

The broad width of peak $A$ is now addressed. The peaks for the ${ }^{3} \mathrm{~B}_{2}$ state in Figure $4 \mathrm{a}$ have a fwhm of $\sim 11 \mathrm{meV}$, which accounts for an ensemble of rovibronic transitions convoluted with the instrumental resolution. On the other hand, the fwhm of peak A is $>30 \mathrm{meV}$. The (4/4)CASSCF/cc-pVTZ calculations find a very low harmonic frequency of $88 \mathrm{~cm}^{-1}$ for a $b_{1}$ mode of the ${ }^{1} \mathrm{~A}_{1}$ state (see Table $\mathrm{S} 1$ in the Supporting Information). This mode corresponds to disrotatory motion of the two methylene groups of OXA, which will lead to the three-membered-ring closure, i.e., formation of cyclopropanone. ${ }^{28}$ The transition state along this $b_{1}$ coordinate was located at the (4/4)CASSCF level, and its geometric parameters are compared with those of $\tilde{\mathrm{X}}$ ${ }^{1} \mathrm{~A}_{1}$ OXA and cyclopropanone in Table S2 in the Supporting Information. ${ }^{66}$ The CASSCF potential energy at the transition state is higher than that at the ${ }^{1} \mathrm{~A}_{1}$ geometry by only $31 \mathrm{~cm}^{-1}$. It was found, however, that the harmonic zero-point vibrational energy overcomes the minute potential energy barrier, as shown in Tables S2 and S3 in the Supporting Information. Furthermore, CASPT2 energy calculations at these CASSCF stationary points strengthen the transition state character of the ${ }^{1} \mathrm{~A}_{1}$ state. Thus, the broad widths of peak $\mathrm{A}$ and the vibrational progression peaks for the $v_{3}$ mode may be ascribed to the short lifetime of $\tilde{X}^{1} \mathrm{~A}_{1}$ OXA. This conclusion is supported by a recent theoretical study of wave packet dynamics on the EOM-CC potential energy surface. ${ }^{33}$ Their estimate of the lifetime of the singlet wave packet in the Franck-Condon region upon photodetachment of the OXA radical anion is $170 \mathrm{fs}$, which corresponds to a line broadening with a fwhm of $\sim 8 \mathrm{meV}$. The broad peak at the base of peak $\mathrm{E}$ appears to have an even broader width than peak $\mathrm{A}$ (Figure 4a). Excitation of the $\mathrm{CO}$ stretching mode in the ${ }^{1} \mathrm{~A}_{1}$ state may significantly alter the level structure or dynamics of the disrotatory mode.

The OXA spectra shown in Figures 3 and 4 have been assigned to the $\tilde{\mathrm{X}}^{1} \mathrm{~A}_{1}$ and $\tilde{\mathrm{a}}^{3} \mathrm{~B}_{2}$ states. The remaining higher eBE portion of the magic-angle spectrum in Figure $2 b$ is expanded in Figure 5a. B3LYP/6-311++G(d,p) calculations find a ${ }^{3} B_{1}$ state of OXA to be a minimum at a $C_{2 v}$ geometry. The calculated geometric parameters are given in Table 2, and the results of harmonic vibrational analysis are provided in Table $S 1$ in the Supporting Information. The eBE of the OXA radical anion relative to the ${ }^{3} B_{1}$ state of OXA is calculated to be $2.793 \mathrm{eV}$, which is close to the eBE of peak A in Figure 5a. Spectral simulations were carried out with the equilibrium geometries and the harmonic vibrational analysis of the DFT calculations. The simulated spectrum is superimposed on the observed spectrum in Figure $5 \mathrm{~b}$. The position of the origin peak of the simulated spectrum was set to that of peak A. The positions and relative intensities of the observed peaks are well reproduced in the simulation, which facilitates their assignments. Peak $\mathrm{A}$ is assigned to be the vibrational ground level of the $\tilde{\mathrm{b}}{ }^{3} \mathrm{~B}_{1}$ state, and its electronic term energy is determined to be $0.883 \pm 0.012 \mathrm{eV}$. The $\beta$ value of peak A is $-0.70 \pm 0.10$. Peaks $\mathrm{B}$ and $\mathrm{C}$ represent the fundamental and overtone levels of the $v_{7}$ mode (CCC bending), respectively. Peaks D and G are the fundamental and overtone levels of the $v_{4}$ mode (CO stretching), respectively. Peaks $\mathrm{E}$ and $\mathrm{F}$ correspond to a progression of the $v_{7}$ mode off peak $\mathrm{D}$, while peak $\mathrm{H}$ is also a progression off peak $\mathrm{G}$. These peak assignments are summarized in Table 1. The appearances of these peaks reflect significant nuclear displacements from the equilibrium geometry of the radical anion to that of $\tilde{b}^{3} \mathrm{~B}_{1}$ OXA along the two normal coordinates (see Table 2). The simulation also predicts a small hot band due to excitation of the $v_{7}$ mode of the $\mathrm{X}^{2} \mathrm{~A}_{2}$ state of the OXA radical anion.

3.2. Photoelectron Spectrum of the Acetylcarbene Radical Anion. In section 3.1, the good quality of the simulation of the a ${ }^{3} \mathrm{~B}_{2}$ OXA spectrum has been demonstrated (Figure $3 \mathrm{~b}$ ). However, the broad background photoelectron signals are also observed in the spectrum. As mentioned in section 1 , the reaction of $\mathrm{O}^{--}$with acetone also produces a structural isomer, the AC radical anion (reaction 2 ). To investigate the possibility that detachment from this isomeric ion accounts for the broad background photoelectrons, an isotopologue of acetone, 1,1, 1 -trideuteroacetone, is used as a reactant in the ion synthesis. ${ }^{37}$

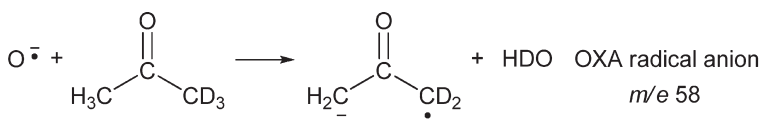

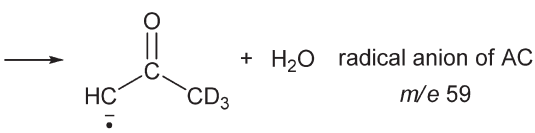

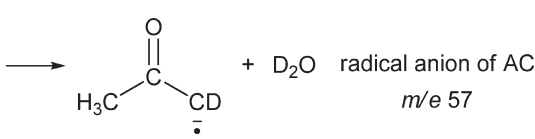

$$
\begin{aligned}
& \longrightarrow \underset{\mathrm{H}_{2} \mathrm{C}_{-}^{-}}{\mathrm{C}_{\mathrm{C}}^{\mathrm{O}}} \underset{\mathrm{CD}_{3}}{ }+\cdot \mathrm{OH} \quad \begin{array}{c}
\text { 1-MVO ion } \\
m / e 60
\end{array}
\end{aligned}
$$

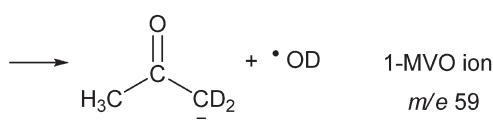

This reaction generates two isotopologues of the AC radical anion (reactions 7 and 8). While one of them has the same mass/charge ratio as that of one of the isotopologues of the 1-MVO ion (reactions 7 and 10), the other isotopologue of the AC radical anion (reaction 8 ) has a unique mass/charge ratio. Figure 6 shows that this ion is cleanly isolated in the time-of-flight mass spectrometry employed in the present work. The photoelectron imaging spectrum of the $m / e 57$ ion, i.e., monodeuterated $\mathrm{AC}$ radical anion, is displayed in Figure $7 \mathrm{~b}$. The spectrum is quite broad with a photoelectron onset at $\mathrm{eBE} \sim 1.6 \mathrm{eV}$. For comparison, Figure 7a shows the imaging spectrum of the $m / e 56$ ions produced from the reaction of undeuterated acetone in the same ion source (reactions 1 and 2). The profile of the monodeuterated AC spectrum matches those of the background photoelectron signals seen in Figure $7 \mathrm{a}$ and Figure $3 \mathrm{~b}$. Thus, it is concluded that the broad background photoelectrons originate from the AC radical anion.

Such a broad, structureless profile of the AC spectrum can be rationalized as follows. Equilibrium geometries of the low-lying states of the $\mathrm{AC}$ radical anion and the ${ }^{3} \mathrm{~A}^{\prime \prime}$ state of $\mathrm{AC}$ were calculated under $C_{s}$ symmetry with the B3LYP/6-311++G(d,p) 


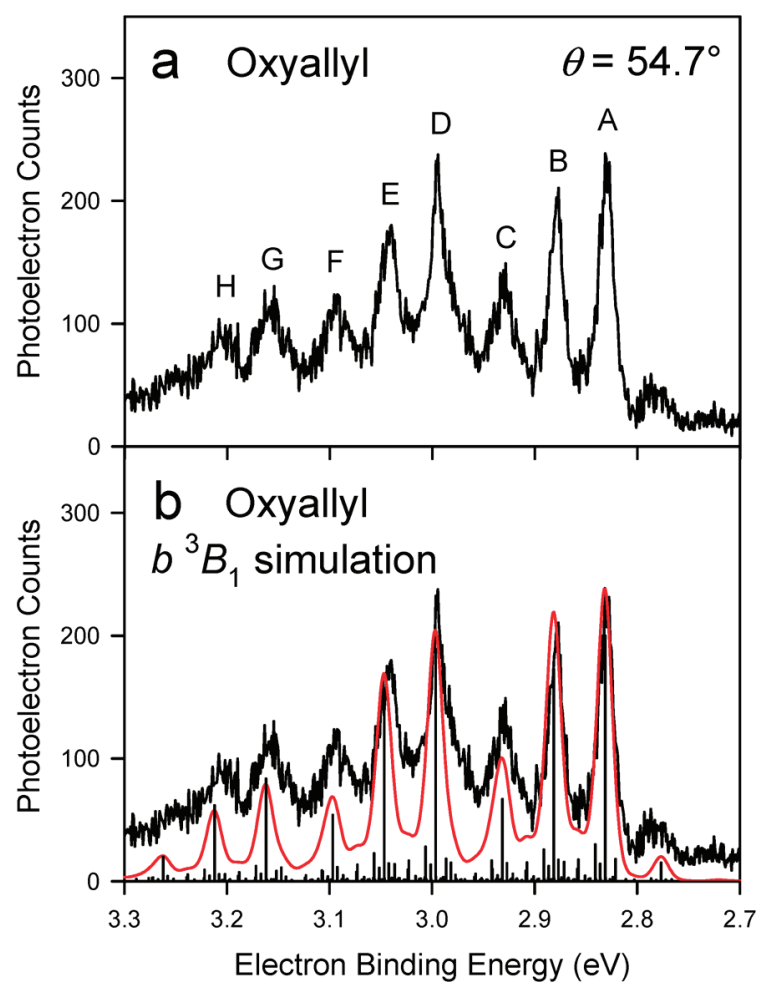

Figure 5. (a) Expansion of the higher eBE portion of the magic-angle spectrum shown in Figure 2b. (b) A simulation of the photoelectron spectrum of the OXA radical anion (red line) that corresponds to detachment to $\tilde{b}^{3} \mathrm{~B}_{1}$ OXA is superimposed on the experimental magicangle spectrum (black line). Simulated individual vibronic transitions (sticks) are convoluted with a Gaussian function of a fwhm of $15 \mathrm{meV}$. The vibrational temperature of the ion was assumed to be $298 \mathrm{~K}$ in the simulation.

method, and the results are summarized in Tables S4 and S5 in the Supporting Information. Four conformational isomers are considered (see Figure 1). The conformation of the methyl group is either staggered or eclipsed with respect to the $\mathrm{CO}$ bond. Also, the $\mathrm{CH}$ bond at the carbene site is either in syn conformation or in anti conformation with respect to the $\mathrm{CO}$ bond. Harmonic vibrational analyses were also performed at the optimized geometries, and the results are provided in Tables S6 and S7 in the Supporting Information.

The lowest potential energy of the AC radical anion in $C_{s}$ nuclear configuration is located at a syn-staggered conformation with a spatial symmetry of $\mathrm{A}^{\prime}$ according to the DFT calculations (Table S4 in the Supporting Information). However, it is found to be a transition state with an imaginary frequency for the $\mathrm{CH}$ out-of-plane bending mode at the carbene center (Table S6 in the Supporting Information). The potential energy minimum is located at a geometry where the $\mathrm{CH}$ bond is bent out of the plane of the heavy atoms by $35.4^{\circ}$. These calculation results are most probably indicative of vibronic coupling between the ${ }^{2} \mathrm{~A}^{\prime}$ and ${ }^{2} \mathrm{~A}^{\prime \prime}$ states. The lowest potential energy of the ${ }^{2} \mathrm{~A}^{\prime \prime}$ state of the radical anion is predicted to be only $1096 \mathrm{~cm}^{-1}$ higher than that of the ${ }^{2} \mathrm{~A}^{\prime}$ state under $C_{s}$ symmetry (Table $\mathrm{S} 4$ in the Supporting Information). Both the $\sigma$ and $\pi$ MOs in which the unpaired electrons of the ${ }^{2} \mathrm{~A}^{\prime}$ and ${ }^{2} \mathrm{~A}^{\prime \prime}$ states reside, respectively, have considerable amplitudes at the carbene center. Therefore, the $\mathrm{CH}$ out-of-plane bending leads to substantial mixing of the two states which are energetically located close to each other. Such

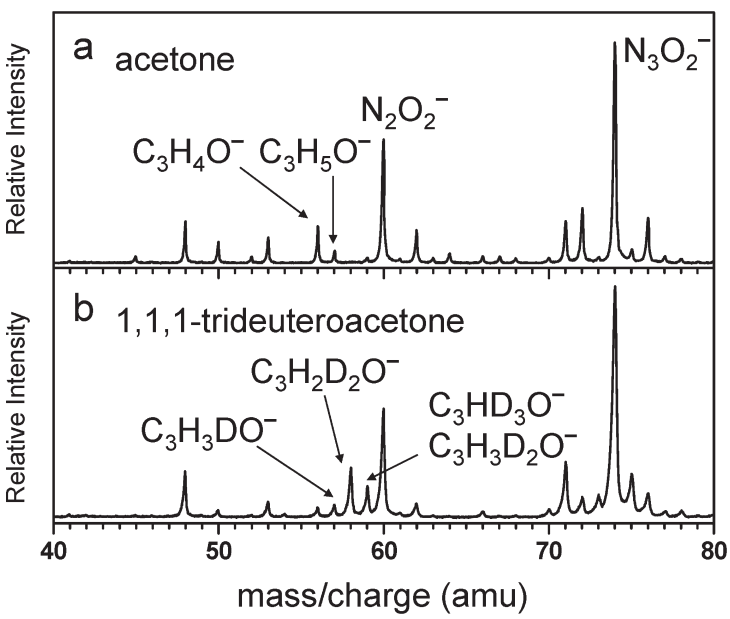

Figure 6. Time-of-flight mass spectra showing the ion products of the reactions of $\mathrm{O}^{--}$with (a) acetone (reactions $1-3$ ) and (b) 1,1,1trideuteroacetone (reactions 6-10) in the pulsed electron impact ion source.

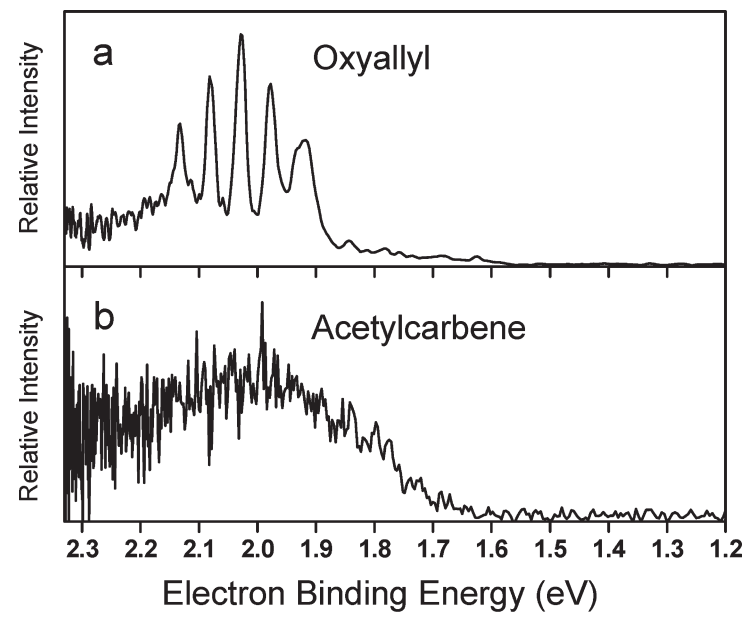

Figure 7. (a) Photoelectron imaging spectrum of the $m / e 56$ ions produced from the reaction of $\mathrm{O}^{-}$with acetone (reactions 1 and 2 ) in the pulsed electron impact ion source. (b) Photoelectron imaging spectrum of the monodeuterated AC radical anion $(\mathrm{m} / \mathrm{e} 57)$ produced from the reaction of $\mathrm{O}^{\circ-}$ with 1,1,1-trideuteroacetone (reaction 8 ) in the pulsed electron impact ion source.

vibronic coupling can distort the adiabatic potential energy surfaces so that the global potential minimum of the radical anion can be at a $C_{1}$ geometry. ${ }^{67,68}$

For the ${ }^{3} \mathrm{~A}^{\prime \prime}$ state of $\mathrm{AC}$, the lowest potential energy in $C_{s}$ nuclear configuration is located at a syn-eclipsed conformation according to the DFT calculations (Table S5 in the Supporting Information). In contrast to the ${ }^{2} \mathrm{~A}^{\prime}$ state of the $\mathrm{AC}$ radical anion, no imaginary frequency is predicted for the carbene-center $\mathrm{CH}$ out-of-plane bending mode of the ${ }^{3} \mathrm{~A}^{\prime \prime}$ state. On the other hand, the potential energy curve of the ${ }^{3} \mathrm{~A}^{\prime \prime}$ state along the methyl internal rotation is quite flat (see Tables S5 and S7 in the Supporting Information). In addition to these substantial differences in the potential energy surface between the radical anion and the carbene states, the DFT calculations also find other significant geometry differences between the two states, e.g., $\mathrm{CO}$ bond length, CC bond length, and OCC bond angle (see Tables S4 and S5 in the Supporting Information). These considerations 


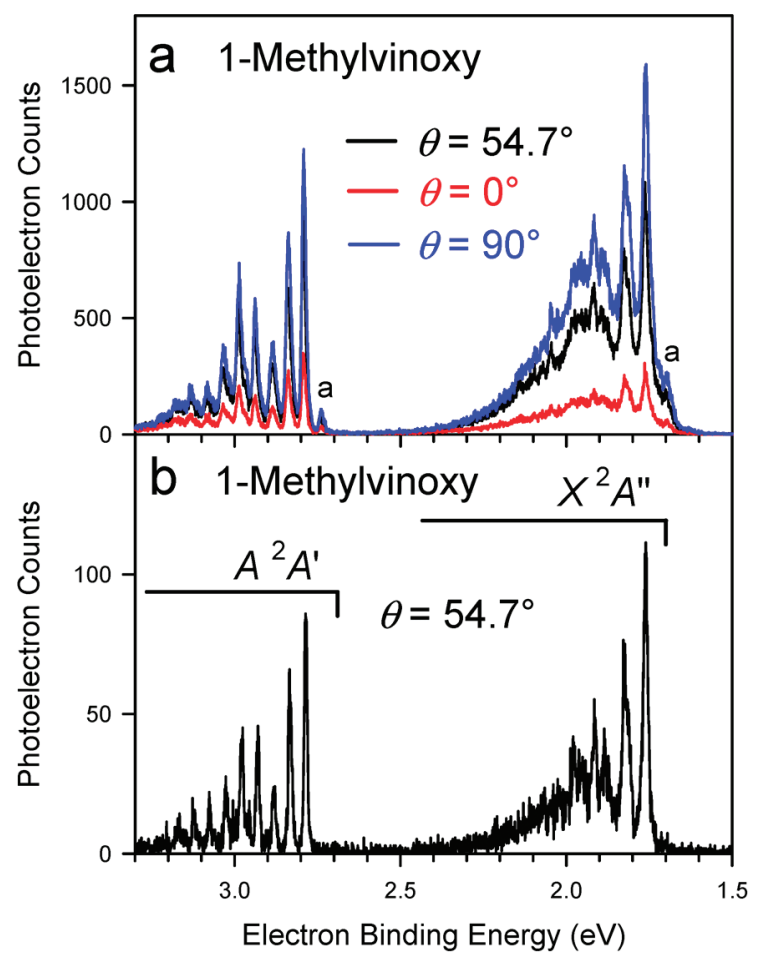

Figure 8. (a) Photoelectron spectra of the 1-MVO ion produced from the reaction of $\mathrm{HO}^{-}$with acetone (reaction 4) in the flowing afterglow ion source at room temperature; $\theta=54.7^{\circ}$ (black), $0^{\circ}$ (red), and $90^{\circ}$ (blue). (b) Magic-angle photoelectron spectrum of the 1-MVO ion produced in the cooled flow tube.

lead us to suspect that the photodetachment from the radical anion to the ${ }^{3} \mathrm{~A}^{\prime \prime}$ state of $\mathrm{AC}$ would result in extensive vibrational progressions for multiple modes, some of which have very low fundamental frequencies, in the photoelectron spectrum. It should be added that the DFT calculations predict the eBE of the $\mathrm{AC}$ radical anion relative to the ${ }^{3} \mathrm{~A}^{\prime \prime}$ state of $\mathrm{AC}$ to be 1.693 $\mathrm{eV}$. All these results of the DFT calculations appear to conform with the observation of the broad, structureless profile of the AC spectrum.

3.3. Photoelectron Spectrum of the 1-Methylvinoxide Ion. The reaction of $\mathrm{O}^{\circ-}$ with acetone also produces the 1-MVO ion (reaction 3). The photoelectron spectrum of the 1 -MVO ion has been reported in the literature. ${ }^{69,70}$ In particular, the most recent study by Neumark and co-workers reports a high-resolution photoelectron imaging spectrum. ${ }^{70}$ The photoelectron spectrum of the 1-MVO ion measured in the present study is compared with this imaging spectrum in this section.

Figure 8a displays the photoelectron spectra of the 1-MVO ion produced in the reaction of $\mathrm{HO}^{-}$with acetone (reaction 4) in the flow tube at room temperature. The spectra exhibit two distinct portions. According to previous studies, ${ }^{69,70}$ the lower eBE portion of the spectra represents detachment to the electronic ground state $\left(\tilde{\mathrm{X}}^{2} \mathrm{~A}^{\prime \prime}\right)$ of the 1-methylvinoxy radical, and the higher eBE portion corresponds to the first excited state $\left(\tilde{\mathrm{A}}^{2} \mathrm{~A}^{\prime}\right)$. The $\beta$ values (see eq 5 ) for the most intense peaks in the lower and higher eBE portions are determined to be $-0.75 \pm 0.05$ and $-0.60 \pm 0.05$, respectively. The spectrum of the $1-\mathrm{MVO}$ ion with lower rotational and vibrational temperatures is shown in Figure $8 \mathrm{~b}$.

B3LYP/6-311++G(d,p) calculations were performed for this system to analyze the spectrum. Geometry optimizations were carried out for the $\tilde{\mathrm{X}}^{1} \mathrm{~A}^{\prime}$ state of the 1-MVO ion and the $\tilde{\mathrm{X}}^{2} \mathrm{~A}^{\prime \prime}$ and $\tilde{\mathrm{A}}^{2} \mathrm{~A}^{\prime}$ states of the 1 -MVO radical under $C_{s}$ symmetry. The optimized geometric parameters are given in Table S8 in the Supporting Information. Note that two conformational isomers are considered. In one conformer the methyl group is staggered against the $\mathrm{CO}$ bond, while it is eclipsed in the other (see Figure 1). Harmonic vibrational analyses were also performed at the equilibrium geometries, and the results are given in Table $S 9$ in the Supporting Information. The EA of the 1-MVO radical is calculated to be $1.743 \mathrm{eV}$, and the electronic term energy of $\tilde{\mathrm{A}}^{2} \mathrm{~A}^{\prime}$ $1-\mathrm{MVO}$ radical is calculated to be $1.001 \mathrm{eV} .^{59}$

Spectral simulations based on the equilibrium geometries and the harmonic vibrational analysis of the DFT calculations were carried out, $^{71}$ and the results are shown in Figures 9 and 10. The position of the origin peak of each simulated spectrum is set to that of peak A of the observed spectrum. Since the harmonic approximation is not quite appropriate for the methyl torsional mode $\left(v_{21}\right)$ of the 1-MVO system (see Tables S8 and S9 in the Supporting Information and ref 70), this mode is excluded from the Franck-Condon factor calculations.

Figure 9 demonstrates that the $\tilde{\mathrm{X}}^{2} \mathrm{~A}^{\prime \prime}$ spectrum is reproduced very well in the simulation. Peak A represents the vibrational ground level (save the $v_{21}$ mode) of the $\mathrm{X}^{2} \mathrm{~A}^{\prime \prime}$ state. The eBE for peak $\mathrm{A}$ is $1.760 \pm 0.004 \mathrm{eV}$, which is in good agreement with the corresponding value reported in ref 70, $1.759 \pm 0.002 \mathrm{eV}$. Note that, as elegantly demonstrated in ref 70 , peak A largely represents transitions to the excited levels of the methyl torsional mode because the methyl conformations are drastically different between $\tilde{\mathrm{X}}^{1} \mathrm{~A}^{\prime} 1$-MVO ion and $\tilde{\mathrm{X}}^{2} \mathrm{~A}^{\prime \prime} 1$-MVO radical (see Table S8 in the Supporting Information). The photoelectron imaging study reports that the EA of the $1-\mathrm{MVO}$ radical is $1.747 \pm 0.002$ $\mathrm{eV}^{70}$ The positions and assignments of the other peaks are summarized in Table 3 . The vibrational levels of the $v_{9}$ (asymmetric CCC stretch) and $v_{13}$ (OCC bend) modes are observed in the spectrum. The activity of these modes in the spectrum is attributed to substantial nuclear displacements along the corresponding normal coordinates from the anion to the radical states (Table S8 in the Supporting Information). The shoulders of peaks $\mathrm{B}, \mathrm{C}$, and $\mathrm{E}$ are associated with the vibrational levels of the $v_{14}$ (CCC bend) mode. Some of these transitions are well resolved in the imaging spectrum. ${ }^{70}$ The relative peak positions and their assignments in the present study accord with those in ref 70. The vibrational temperature of the 1-MVO ions produced in the flow tube at room temperature is much higher than that of the ions generated in ref 70, and a hot band is observed in the spectrum shown in Figure 8a (peak a). The peak position corresponds to the fundamental vibrational frequency of the $v_{13}$ mode of the anion (Table 3 ).

The simulation also reproduces the $\tilde{\mathrm{A}}^{2} \mathrm{~A}^{\prime}$ spectrum very well, as shown in Figure 10. Thus, peak $A$ is assigned to be the vibrational ground level of $\tilde{\mathrm{A}}^{2} \mathrm{~A}^{\prime}$ 1-MVO radical. The energy separation between peak $\mathrm{A}^{\prime}$ s of the $\tilde{\mathrm{X}}^{2} \mathrm{~A}^{\prime \prime}$ and $\tilde{\mathrm{A}}^{2} \mathrm{~A}^{\prime}$ states is 1.026 $\pm 0.012 \mathrm{eV}$, which is in good agreement with the findings reported in ref 70 . Note that, according to ref 70, the electronic term energy of the $\tilde{\mathrm{A}}^{2} \mathrm{~A}^{\prime}$ state is $1.037 \pm 0.002 \mathrm{eV}$, accounting for the methyl torsional levels. Several modes are active in the $\widetilde{A}^{2} \mathrm{~A}^{\prime}$ spectrum (see Table 3 ). The $v_{5}$ mode represents the CC stretch motion that involves the $\mathrm{C}$ atom of the methylene group, while the $v_{7}$ mode corresponds to the $\mathrm{CH}_{2}$ scissor motion of the methylene group. The asymmetric OCC stretch that involves the $\mathrm{C}$ atom of the methyl group constitutes the $v_{9}$ mode. The inplane wagging of the methyl group is the $v_{14}$ mode. Again, the 


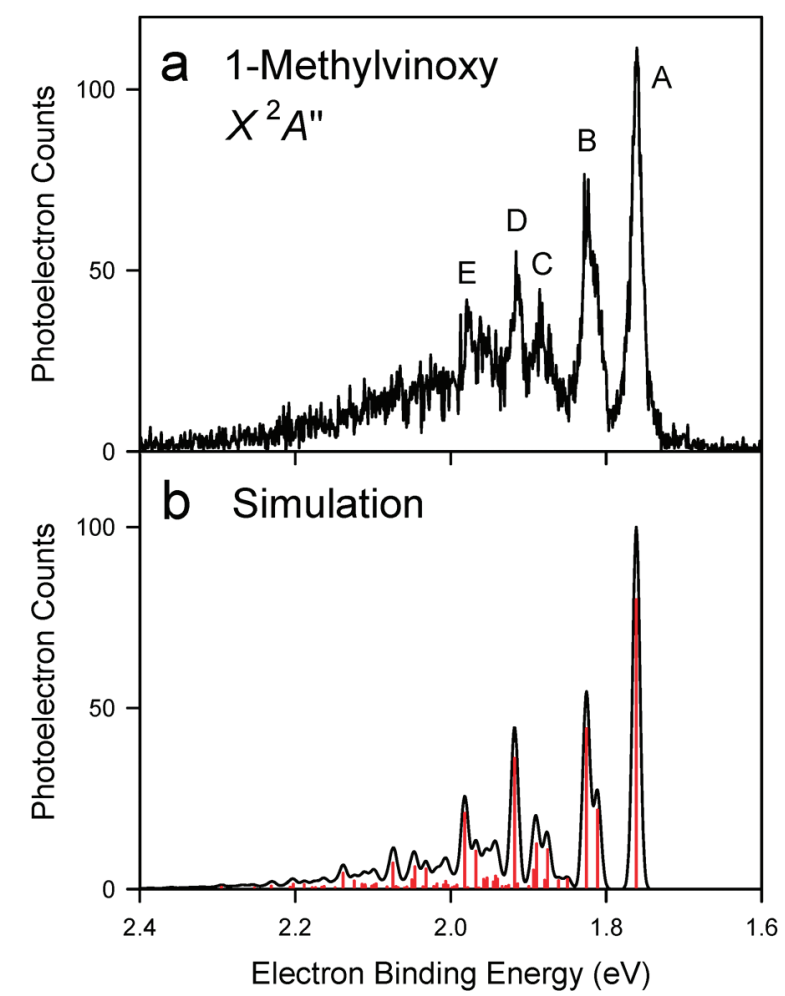

Figure 9. (a) $\tilde{\mathrm{X}}^{2} \mathrm{~A}^{\prime \prime}$ portion of the photoelectron spectrum of the $1-\mathrm{MVO}$ ion shown in Figure 8b. (b) Simulated individual vibronic transitions (red sticks) are convoluted with a Gaussian function of a fwhm of $11 \mathrm{meV}$ (black line). The vibrational temperature of the ion was assumed to be $0 \mathrm{~K}$.

findings in the present study about the vibronic levels of the $\tilde{\mathrm{A}}^{2} \mathrm{~A}^{\prime}$ state accord with those in ref 70 . Note that the present study reports additional vibronic peaks that are not observed in ref 70 . Also, the hot band seen in Figure $8 \mathrm{a}$ (peak a) is a transition from the fundamental level of the $v_{14}$ mode of the 1-MVO ion to the vibrational ground level of $\tilde{\mathrm{A}}^{2} \mathrm{~A}^{\prime}$ 1-MVO radical.

\section{DISCUSSION}

4.1. Vibronic Structure of Oxyallyl. OXA is isoelectronic with TMM. It is fruitful to compare the vibronic structures of these diradicals to analyze the effects of the $\mathrm{O}$ atom substitution. Detailed analysis of the electronic structure of TMM has been

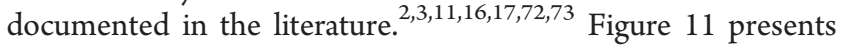
schematic representations of the $\pi$ MOs of TMM in $D_{3 h}$ symmetry. The symmetry-enforced degeneracy of the $\psi_{2}\left(\mathrm{e}_{x}^{\prime \prime}\right)$ and $\psi_{3}\left(\mathrm{e}_{y}^{\prime \prime}\right)$ orbitals is associated with the complicated electronic structure of the low-lying states of TMM. ${ }^{2,3}$ There are several ways for four electrons to occupy the four $\pi$ MOs. In the most stable configurations, two electrons reside in the lowest orbital, $\psi_{1}\left(1 \mathrm{a}_{2}{ }^{\prime \prime}\right)$, and the remaining two electrons can be distributed in the degenerate orbitals. For the triplet spin configurations, $\psi_{2}$ and $\psi_{3}$ accommodate one electron each: ${ }^{2,3}$

$$
\Psi\left({ }^{3} \mathrm{~A}_{2}{ }^{\prime}\right)=\frac{1}{\sqrt{2}}\left(\left|\psi_{1} \bar{\psi}_{1} \psi_{2} \bar{\psi}_{3}\right\rangle-\left|\psi_{1} \bar{\psi}_{1} \psi_{3} \bar{\psi}_{2}\right\rangle\right)
$$

Here, only one of the three spin configurations is presented. On the other hand, for the singlet spin configurations, three states arise: $:^{2,3}$

$$
\Psi\left({ }^{1} \mathrm{E}_{x}{ }^{\prime}\right)=\frac{1}{\sqrt{2}}\left(\left|\psi_{1} \bar{\psi}_{1} \psi_{2} \bar{\psi}_{2}\right\rangle-\left|\psi_{1} \bar{\psi}_{1} \psi_{3} \bar{\psi}_{3}\right\rangle\right)
$$

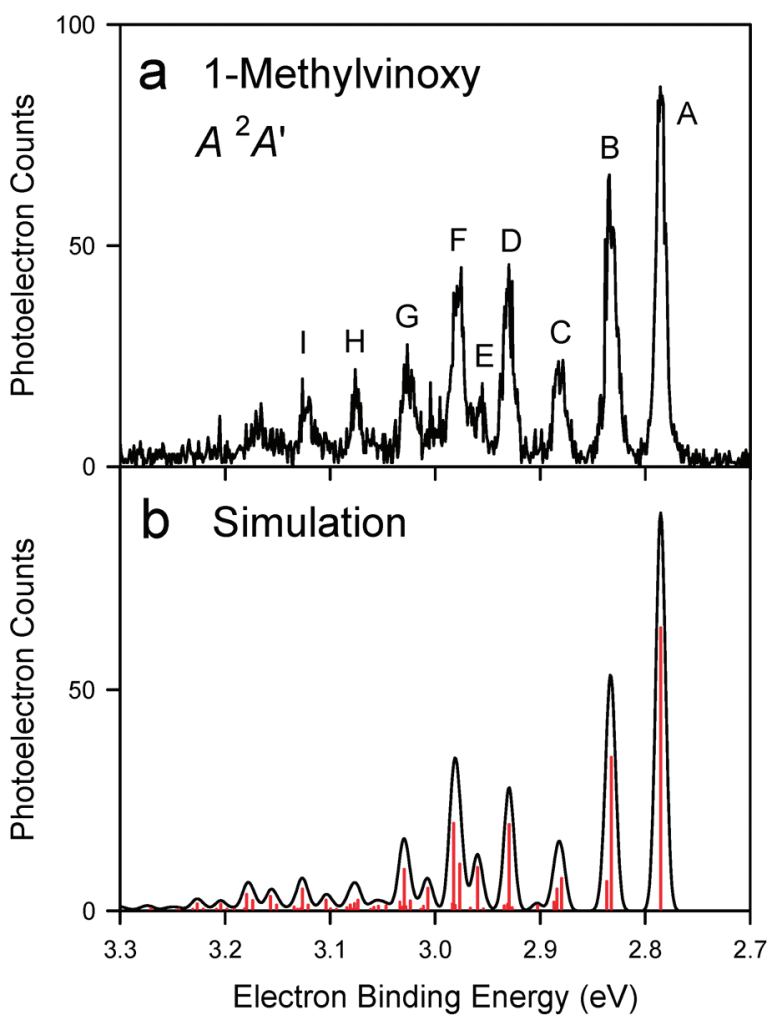

Figure 10. (a) $\tilde{A}^{2} \mathrm{~A}^{\prime}$ portion of the photoelectron spectrum of the 1-MVO ion shown in Figure 8b. (b) Simulated individual vibronic transitions (red sticks) are convoluted with a Gaussian function of a fwhm of $11 \mathrm{meV}$ (black line). The vibrational temperature of the ion was assumed to be $0 \mathrm{~K}$.

$$
\begin{gathered}
\Psi\left({ }^{1} \mathrm{E}_{y}{ }^{\prime}\right)=\frac{1}{\sqrt{2}}\left(\left|\psi_{1} \bar{\psi}_{1} \psi_{2} \bar{\psi}_{3}\right\rangle+\left|\psi_{1} \bar{\psi}_{1} \psi_{3} \bar{\psi}_{2}\right\rangle\right) \\
\Psi\left({ }^{1} \mathrm{~A}_{1}{ }^{\prime}\right)=\frac{1}{\sqrt{2}}\left(\left|\psi_{1} \bar{\psi}_{1} \psi_{2} \bar{\psi}_{2}\right\rangle+\left|\psi_{1} \bar{\psi}_{1} \psi_{3} \bar{\psi}_{3}\right\rangle\right)
\end{gathered}
$$

Note that, with the $D_{3 h}$ MOs being used, two of the three singlet states form a degenerate pair, ${ }^{1} \mathrm{E}_{x}^{\prime}$ and ${ }^{1} \mathrm{E}_{y}^{\prime}$ (eqs 12 and 13). ${ }^{2,3}$ Neglecting the common contributions of the two electrons occupying $\psi_{1}$, the energies of these states can be represented as follows: ${ }^{2,3}$

$$
\begin{aligned}
& E\left({ }^{3} \mathrm{~A}_{2}{ }^{\prime}\right)=2 h_{2}+J_{2,3}-K_{2,3} \\
& E\left({ }^{1} \mathrm{E}_{x}{ }^{\prime}\right)=2 h_{2}+J_{2,2}-K_{2,3} \\
& E\left({ }^{1} \mathrm{E}_{y}{ }^{\prime}\right)=2 h_{2}+J_{2,3}+K_{2,3} \\
& E\left({ }^{1} \mathrm{~A}_{1}{ }^{\prime}\right)=2 h_{2}+J_{2,2}+K_{2,3}
\end{aligned}
$$

where $h_{i}$ is the one-electron integral involving $\psi_{i}$, and $J_{i, j}$ and $K_{i, j}$ are Coulomb and exchange integrals, respectively, involving $\psi_{i}$ and $\psi_{j}$. Derivation of eqs 15-18 utilizes the properties of the degeneracy of $\psi_{2}$ and $\psi_{3}$, i.e., $h_{2}=h_{3}$ and $J_{2,2}=J_{3,3}$. Note that another relation holds for the degenerate orbitals, ${ }^{2,3}$ i.e., $J_{2,2}-J_{2,3}=2 K_{2,3}$.

Since $J_{2,2}>J_{2,3}$, eqs $15-18$ suggest that the ${ }^{3} \mathrm{~A}_{2}{ }^{\prime}$ state is the lowest electronic state of TMM, ${ }^{2,3}$ which was first confirmed by ESR measurements ${ }^{9}$ and later corroborated by photoelectron spectroscopic measurements of the TMM radical anion. ${ }^{13,14}$ 
Table 3. Peak Positions and Assignments of Photoelectron Spectrum of 1-Methylvinoxide Ion

\begin{tabular}{|c|c|c|c|c|}
\hline 1-MVO radical & peak $^{a}$ & peak position ${ }^{b}\left(\mathrm{~cm}^{-1}\right)$ & assignments $^{c}$ & peak position $^{d}\left(\mathrm{~cm}^{-1}\right)$ \\
\hline \multirow[t]{6}{*}{$\tilde{\mathrm{X}}^{2} \mathrm{~A}^{\prime \prime}$} & a & $-500 \pm 30$ & $13_{1}^{0}$ & \\
\hline & A & 0 & $0_{0}^{0}$ & \\
\hline & B & $520 \pm 20$ & $13_{0}^{1}$ & 515 \\
\hline & $\mathrm{C}$ & $1005 \pm 30$ & $13_{0}^{2}$ & 1048 \\
\hline & $\mathrm{D}$ & $1250 \pm 25$ & $9_{0}^{1}$ & 1247 \\
\hline & E & $1755 \pm 30$ & $9_{0}^{1} 13_{0}^{1}$ & 1767 \\
\hline \multirow[t]{10}{*}{$\tilde{\mathrm{A}}^{2} \mathrm{~A}^{\prime}$} & $\mathrm{a}$ & $-420 \pm 15$ & $14_{1}^{0}$ & \\
\hline & A & 0 & $0_{0}^{0}$ & \\
\hline & B & $380 \pm 15$ & $14_{0}^{1}$ & 395 \\
\hline & $\mathrm{C}$ & $775 \pm 25$ & $14_{0}^{2}\left(13_{0}^{1} 14_{0}^{1}\right)$ & 794 \\
\hline & $\mathrm{D}$ & $1175 \pm 20$ & $9_{0}^{1}$ & 1191 \\
\hline & E & $1370 \pm 25$ & $7_{0}^{1}$ & \\
\hline & $\mathrm{F}$ & $1565 \pm 25$ & $5_{0}^{1}\left(9_{0}^{1} 14_{0}^{1}\right)$ & 1573 \\
\hline & G & $1935 \pm 30$ & $5_{0}^{1} 14_{0}^{1}$ & \\
\hline & $\mathrm{H}$ & $2330 \pm 35$ & & \\
\hline & I & $2730 \pm 45$ & & \\
\hline
\end{tabular}

${ }^{a}$ The peak labels are shown in Figures $8-10 .{ }^{b}$ The peak positions are given relative to the vibrational ground level of the corresponding electronic state. ${ }^{c}$ See the text for descriptions of the normal modes. ${ }^{d}$ From ref 70.

Equations 16-18 clearly indicate that the lowest singlet state of TMM is ${ }^{1} \mathrm{E}^{\prime}$. This degenerate state is subject to Jahn-Teller effects. ${ }^{3,72,74}$ Linear Jahn-Teller effects in the ${ }^{1} E^{\prime}$ state $^{72}$ have been discussed in terms of configuration interactions. ${ }^{3,16}$ Configurations generated from single-electron excitations $\psi_{1} \rightarrow \psi_{2}$ and $\psi_{2} \rightarrow \psi_{4}$ significantly mix into the wave functions shown in eqs 12 and $13 .^{16}$ The resultant wave function for the ${ }^{1} \mathrm{E}_{x}{ }^{\prime}$ state bears a character of double bond between the central $\mathrm{C}$ atom and one of the peripheral ones and an unpaired electron localized on each of the two remaining $\mathrm{C}$ atoms. ${ }^{3}$ On the other hand, the ${ }^{1} \mathrm{E}_{y}{ }^{\prime}$ state has a correspondence with an allyl radical and an unpaired electron localized on the remaining $\mathrm{C}$ atom. ${ }^{3}$ Distortion from the $D_{3 h}$ to $C_{2 v}$ geometries along the $\mathrm{e}^{\prime}$ normal coordinate that is associated with $\mathrm{CC}$ stretching motion lifts the degeneracy of the ${ }^{1} \mathrm{E}_{x}{ }^{\prime}$ (which becomes ${ }^{1} \mathrm{~A}_{1}$ under $C_{2 v}$ symmetry) and ${ }^{1} \mathrm{E}_{y}{ }^{\prime}\left({ }^{1} \mathrm{~B}_{2}\right)$ states, ${ }^{72}$ but the adiabatic energies of the two states at the corresponding equilibrium geometries along the pseudorotation path would remain identical to each other if the vibronic coupling operated at the first order only. Pseudo-Jahn-Teller interaction between the ${ }^{1} \mathrm{~A}_{1}$ states under $C_{2 v}$ symmetry (which correspond to the states represented by eqs 12 and 14) perturbs the pseudorotation, and the ${ }^{1} \mathrm{~A}_{1}$ state becomes the minimum while the ${ }^{1} \mathrm{~B}_{2}$ state becomes the transition state ${ }^{75}$ with a small adiabatic energy separation. ${ }^{72,76}$ However, the ${ }^{1} \mathrm{~B}_{2}$ state undergoes further energy lowering owing to torsion of the methylene group lying along the $C_{2}$ axis out of the molecular plane, which turns the ${ }^{1} B_{2}$ state into the ${ }^{1} B_{1}$ state. ${ }^{3,17,72}$ As a result, the adiabatic energy of the ${ }^{1} B_{1}$ state is expected to be several kilojoules per mole lower than that of the ${ }^{1} \mathrm{~A}_{1}$ state. ${ }^{17,18,72}$ The ${ }^{1} \mathrm{~A}_{1}$ state was observed in the photoelectron spectrum of the TMM radical anion, and the energy separation between the $\tilde{\mathrm{X}}^{3} \mathrm{~A}_{2}{ }^{\prime}$ and $\tilde{\mathrm{b}}^{1} \mathrm{~A}_{1}$ states was determined to be $0.699 \pm 0.006 \mathrm{eV} .^{13,14}$ The $\tilde{a}^{1} \mathrm{~B}_{1}$ state was not observed in the photoelectron spectrum because of the poor Franck-Condon overlap with the $\tilde{\mathrm{X}}^{2} \mathrm{E}^{\prime \prime}$ state of the TMM radical anion.

Substitution of one of the methylene groups in TMM for an $\mathrm{O}$ atom lifts the degeneracy of $\psi_{2}$ and $\psi_{3}$ (see Figure 11), $1,28,30$ and the highest symmetry that OXA can take is $C_{2 v}$. In such a nondegenerate case, the energies of the states represented by
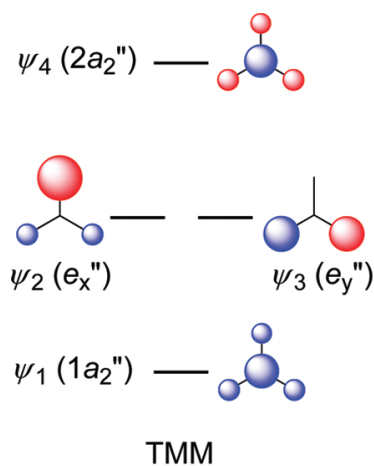

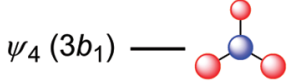

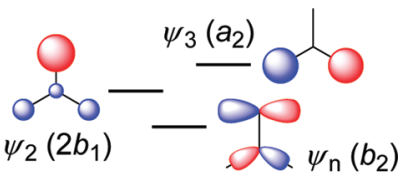

Figure 11. Schematic representation of $\pi$ molecular orbitals of TMM (left) and OXA (right). Note that an in-plane molecular orbital is also shown for OXA.

$$
\begin{aligned}
& \text { eqs } 11-14 \text { are }^{2,3} \\
& \qquad\left({ }^{3} \mathrm{~B}_{2}\right)=h_{2}+h_{3}+J_{2,3}-K_{2,3} \\
& \begin{aligned}
E\left({ }^{1} \mathrm{~A}_{1}\right)= & 2 c_{2}{ }^{2} h_{2}+2 c_{3}{ }^{2} h_{3}+c_{2}{ }^{2} J_{2,2}+c_{3}{ }^{2} J_{3,3} \\
& -\left[\left\{2 c_{2}{ }^{2} h_{2}-2 c_{3}{ }^{2} h_{3}+c_{2}{ }^{2} J_{2,2}\right.\right. \\
& \left.\left.-c_{3}{ }^{2} J_{3,3}\right\}^{2}+4 c_{2}{ }^{2} c_{3}{ }^{2} K_{2,3}{ }^{2}\right]^{1 / 2} \\
E\left({ }^{1} \mathrm{~B}_{2}\right)=h_{2}+h_{3}+J_{2,3}+K_{2,3} & \\
E\left({ }^{1} \mathrm{~A}_{1}\right)= & 2 c_{2}{ }^{2} h_{2}+2 c_{3}{ }^{2} h_{3}+c_{2}{ }^{2} J_{2,2}+c_{3}{ }^{2} J_{3,3} \\
& +\left[\left\{2 c_{2}{ }^{2} h_{2}-2 c_{3}{ }^{2} h_{3}+c_{2}{ }^{2} J_{2,2}\right.\right. \\
& \left.\left.-c_{3}{ }^{2} J_{3,3}\right\}^{2}+4 c_{2}{ }^{2} c_{3}{ }^{2} K_{2,3}{ }^{2}\right]^{1 / 2}
\end{aligned}
\end{aligned}
$$

The equal weights of the two configurations in eqs 12 and 14 should be replaced with $c_{2}$ and $c_{3}$ for the nondegenerate system in general. The analytic expression of energy given in eq 20 is informative because it clearly indicates that, as the energy separation of the two orbitals increases, the lower ${ }^{1} \mathrm{~A}_{1}$ state is 
stabilized. If the energy separation is large enough, then the ${ }^{1} \mathrm{~A}_{1}$ state can be lower in energy than the ${ }^{3} \mathrm{~B}_{2}$ state. ${ }^{2,3}$

The present photoelectron spectroscopic study verifies that the lowest electronic state of OXA is singlet. The spectral simulation shown in Figures $3 \mathrm{~b}$ and $4 \mathrm{~b}$ unambiguously identifies the vibronic peaks of the $\tilde{a}^{3} \mathrm{~B}_{2}$ state. The assignment of the $\tilde{\mathrm{X}}^{1} \mathrm{~A}_{1}$ state is based on and/or associated with (1) its distinct photoelectron angular distributions, (2) its near degeneracy with the a ${ }^{3} \mathrm{~B}_{2}$ state, (3) observation of the vibrational peaks of the $\mathrm{CO}$ stretching mode, and (4) the broad line width implying a flat potential energy curve or a potential energy maximum along the coordinate of disrotatory motion of the two methylene groups around the OXA radical anion geometry. The last point is noteworthy because it suggests that OXA is an unstable species and it is perhaps impossible to trap this molecule for steady-state spectroscopic measurements. Thus, negative ion photoelectron spectroscopy yet again presents itself as a valuable experimental technique to explore reactive intermediates. ${ }^{77}$

The electronic configuration of the $\tilde{\mathrm{X}}^{2} \mathrm{E}^{\prime \prime}$ state of the TMM radical anion is depicted in Figure 12. This ground state is also subject to linear Jahn-Teller effects, and the minimum of the adiabatic potential energy is located at a $C_{2 v}$ geometry. ${ }^{14}$ In the ${ }^{2} \mathrm{~B}_{1}$ state, which is correlated with one of the components of the degenerate state in $D_{3 h}$ symmetry, the $a_{2}$ orbital $\left(\psi_{3}\right.$ in Figure 11) is doubly occupied and enhanced antiphase interaction of the $\pi$ electrons between the peripheral $\mathrm{C}$ atoms widens the CCC angle that the $C_{2}$ axis bisects. ${ }^{14}$ In contrast, the interaction is more favorable in the ${ }^{2} \mathrm{~A}_{2}$ state (the other component of the $D_{3 h}$ degenerate state) where the $b_{1}$ orbital $\left(\psi_{2}\right.$ in Figure 11) is doubly occupied, and the CCC angle becomes narrower. ${ }^{14}$ Consequently, detachment from either of the two states of the radical anion to $\tilde{\mathrm{X}}{ }^{3} \mathrm{~A}_{2}^{\prime} \mathrm{TMM}$, which has $D_{3 h}$ symmetry at the equilibrium geometry, ${ }^{3}$ activates the wave packet motion along the CCC bending coordinate. Indeed, the corresponding vibrational progression was observed in the photoelectron spectrum. ${ }^{13,14}$

On the other hand, there is no degeneracy of the frontier MOs of the OXA radical anion (Figure 11). Introduction of the $\mathrm{O}$ atom stabilizes the $b_{1}$ orbitals, and the ground state of the radical anion is ${ }^{2} \mathrm{~A}_{2}$ (Figure 12). ${ }^{78}$ Analogous to the TMM system, detachment from the $\tilde{\mathrm{X}}{ }^{2} \mathrm{~A}_{2}$ state of the radical anion to $\tilde{\mathrm{a}}^{3} \mathrm{~B}_{2}$ OXA leads to appearance of a vibrational progression of the CCC bending mode in the spectrum. The fundamental frequency of the CCC bending mode of $\tilde{a}^{3} \mathrm{~B}_{2}$ OXA is $405 \pm 10 \mathrm{~cm}^{-1}$, close to that of $\tilde{X}^{3} \mathrm{~A}_{2}{ }^{\prime} \mathrm{TMM},{ }^{14} 425 \pm 10 \mathrm{~cm}^{-1}$. Thus, the $\tilde{a}^{3} \mathrm{~B}_{2}$ portion of the OXA spectrum appreciably resembles the $\tilde{\mathrm{X}}^{3} \mathrm{~A}_{2}^{\prime}$ portion of the TMM spectrum. ${ }^{13,14,79}$

The spectral profiles for $\tilde{\mathrm{X}}{ }^{1} \mathrm{~A}_{1}$ OXA and $\tilde{\mathrm{b}}^{1} \mathrm{~A}_{1} \mathrm{TMM}$ are compared next. It is not straightforward to explain the spectral profile of $\tilde{b}^{1} \mathrm{~A}_{1}$ TMM in terms of detachment from the MOs schematically shown in Figures 11 and 12, because the wave function of the $\tilde{b}^{1} \mathrm{~A}_{1}$ state has a multideterminantal character. ${ }^{2,3}$ For instance, detachment from the $b_{1}$ orbital in the ${ }^{2} B_{1}$ state of the TMM radical anion leaves a closed-shell configuration for TMM. This electronic configuration alone, however, does not fully describe the ${ }^{1} \mathrm{~A}_{1}$ state, because two closed-shell configurations should have equal weights in the wave function (see eq 12 and Figure 12). It is more illuminating to take a linear combination of the two degenerate orbitals shown in Figure $11 .{ }^{16}$ In this representation, ${ }^{3}$ it is easier to see that an unpaired electron is localized on one peripheral $\mathrm{C}$ atom in each of the transformed degenerate orbitals in the ${ }^{1} A_{1}$ state, while the bond between the

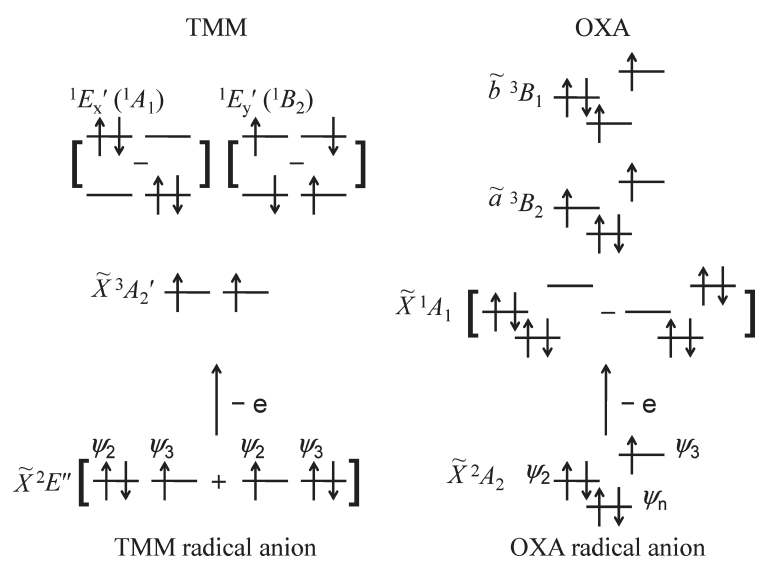

Figure 12. Schematic representation of the principal electronic configurations of TMM (left), OXA (right), and their corresponding radical anions. Only the $\psi_{2}$ and $\psi_{3}$ orbitals are shown for TMM, while the $\psi_{n}$ orbital is also shown for OXA (see Figure 11).

central $\mathrm{C}$ atom and the remaining peripheral $\mathrm{C}$ atom has a double-bond character. ${ }^{16}$ Addition of an electron to these degenerate orbitals of the ${ }^{1} \mathrm{~A}_{1}$ state results in the degenerate ground state of the TMM radical anion. Since these orbitals are largely nonbonding, there are only minimal nuclear displacements from the geometry of the ground state of the radical anion to that of the ${ }^{1} \mathrm{~A}_{1}$ state of TMM, explaining the absence of large vibrational progressions in the $\tilde{b}^{1} A_{1}$ TMM spectrum. ${ }^{13,14}$ It should be noted, however, that none of the CC bonds in $\tilde{\mathrm{X}}^{2} \mathrm{E}^{\prime \prime}$ TMM radical anion has as strong a double-bond character as the unique $C C$ bond in $\tilde{b}{ }^{1} A_{1}$ TMM. The $\tilde{b}{ }^{1} A_{1}$ TMM spectrum appears to show a weak, rather broad band where the fundamental level of the CC stretching mode is expected. ${ }^{20}$

The situation is quite similar for the transition from $\tilde{\mathrm{X}}^{2} \mathrm{~A}_{2}$ OXA radical anion to $\tilde{\mathrm{X}}{ }^{1} \mathrm{~A}_{1}$ OXA. With the orbital degeneracy lifted, the electron configuration of the $\tilde{\mathrm{X}}^{2} \mathrm{~A}_{2}$ state of the radical anion has a strong single-determinant character, ${ }^{80}$ where the CASSCF occupation number of $\psi_{2}$ is 1.93 . On the other hand, the main configuration of $\tilde{\mathrm{X}}^{1} \mathrm{~A}_{1}$ OXA is $\left|\psi_{1} \bar{\psi}_{1} \psi_{2} \bar{\psi}_{2}\right\rangle$, but the wave function still has a significant contribution from $\left|\psi_{1} \psi_{1} \psi_{3} \psi_{3}\right\rangle$ configuration, $^{28,29}$ and the CASSCF occupation number of $\psi_{2}$ is 1.44. As schematically shown in Figure 11, $\psi_{2}$ has a $\mathrm{CO}$ antibonding character. ${ }^{21,30}$ Thus, photodetachment from $\tilde{\mathrm{X}}{ }^{2} \mathrm{~A}_{2}$ OXA radical anion to $\tilde{\mathrm{X}}{ }^{1} \mathrm{~A}_{1}$ OXA significantly shortens the $\mathrm{CO}$ bond length. As a result, the fundamental peak of the $\mathrm{CO}$ stretching mode of $\tilde{\mathrm{X}}^{1} \mathrm{~A}_{1}$ OXA carries some intensity, and even the overtone peak is noticeable in the spectrum (Figures 3 and 4). Relevant to this discussion is the fundamental vibrational frequency of the $\mathrm{CO}$ stretching mode. Analogous to TMM, the diradical nature of $\tilde{\mathrm{X}}^{1} \mathrm{~A}_{1}$ OXA confers a double-bond character on the $\mathrm{CO}$ bond. ${ }^{3,23,28,30}$ The fundamental frequency can be estimated to be $1680 \pm 50 \mathrm{~cm}^{-1}$ from the spectra shown in Figures 3 and 4. This value can be compared with that of the corresponding mode of acetone, ${ }^{81} 1731 \mathrm{~cm}^{-1}$. Previous theoretical studies have suggested that the contribution of the zwitterionic resonance structure (see Figure 1 ) is only modest in $\tilde{\mathrm{X}}^{1} \mathrm{~A}_{1}$ OXA. ${ }^{23,28,30}$

Electronic structure calculations find quite flat potential energy surfaces for the ${ }^{1} \mathrm{~A}_{1}$ states of both TMM and OXA along the corresponding coordinates of three-membered-ring formation. ${ }^{17,23,24}$ In particular, the photoelectron spectrum of the OXA radical anion shows broad line widths for the vibronic 
peaks associated with $\tilde{\mathrm{X}}{ }^{1} \mathrm{~A}_{1} \mathrm{OXA}$, implying its transition state nature. $^{33,82}$

As stated earlier, the ${ }^{1} \mathrm{~A}_{1}$ and ${ }^{1} \mathrm{~B}_{2}$ states of $\mathrm{TMM}$ are vibronically coupled with each other. The vibrational peak at $325 \mathrm{~cm}^{-1}$ in the $\tilde{\mathrm{b}}^{1} \mathrm{~A}_{1}$ TMM spectrum ${ }^{13,14}$ may represent the Jahn-Teller active mode. ${ }^{14,20}$ The absence of the vibronic peaks directly belonging to the ${ }^{1} \mathrm{~B}_{2}$ state of TMM in the spectrum has been attributed to its saddle point nature at the $C_{2 v}$ planar equilibrium geometry. 3,13

The photoelectron spectrum of the OXA radical anion exhibits no evident sign of pseudo-Jahn-Teller interaction between the ${ }^{1} \mathrm{~A}_{1}$ and ${ }^{1} \mathrm{~B}_{2}$ states of OXA. CASPT 2 calculations at the CASSCF optimized geometries suggest that the ${ }^{1} B_{2}$ state is energetically accessible in the present photoelectron spectroscopic measurements because it lies $1.346 \mathrm{eV}$ higher in adiabatic energy than the ${ }^{1} \mathrm{~A}_{1}$ state of OXA (see Supporting Information). The CASSCF calculations find one imaginary frequency for $a b_{2}$ mode of the ${ }^{1} \mathrm{~B}_{2}$ state, which corresponds to CCC asymmetric stretching motion. It should be remembered that this mode is equivalent to an asymmetric component (with respect to the $C_{2 v}$ subgroup) of the $\mathrm{e}^{\prime}$ mode of TMM that is responsible for linear Jahn-Teller coupling in the ${ }^{1} \mathrm{E}^{\prime}$ state. ${ }^{72}$ Strong pseudo-Jahn-Teller interaction between the ${ }^{1} \mathrm{~A}_{1}$ and ${ }^{1} \mathrm{~B}_{2}$ states of OXA can turn the ${ }^{1} \mathrm{~B}_{2}$ state into a transition state. ${ }^{67,68,83}$ It is conceivable that the photodetachment transition intensity is distributed among a large number of vibronic states ${ }^{68}$ such that no clear vibronic feature of the ${ }^{1} B_{2}$ state is observed in the spectrum of the OXA radical anion. Alternatively, the short lifetime of the ${ }^{1} B_{2}$ state may cause excessive line broadening.

The photoelectron spectrum of the OXA radical anion also shows the vibronic peaks of $\tilde{b}^{3} B_{1}$ OXA. Detachment from the $b_{2}$ orbital of the radical anion leads to formation of the ${ }^{3} B_{1}$ state (see Figures 11 and 12). Since the corresponding orbital in the TMM radical anion is associated with the $\mathrm{C}-\mathrm{H} \sigma$ bonds and it is much more stable than the $b_{2}$ orbital of the OXA radical anion, there is no counterpart observed in the photoelectron spectrum of the TMM radical anion in the same energy range. This detachment from the OXA radical anion is analogous to detachment from the 1-MVO ion to form $\tilde{\mathrm{A}}^{2} \mathrm{~A}^{\prime}$ 1-MVO radical (see also section 4.3). The eBE of $\tilde{b}^{3} B_{1}$ OXA is very similar to that of $\tilde{\mathrm{A}}{ }^{2} \mathrm{~A}^{\prime} 1-\mathrm{MVO}$ radical. The corresponding photoelectrons have similar angular distributions. The active modes in the $\tilde{\mathrm{b}}^{3} \mathrm{~B}_{1}$ OXA spectrum, $v_{4}$ and $v_{7}$, are equivalent to $v_{9}$ and $v_{14}$ of $\tilde{\mathrm{A}}^{2} \mathrm{~A}^{\prime} 1$-MVO radical, respectively, which are also active in the photoelectron spectrum of the 1-MVO ion.

4.2. Vibronic Structure of Acetyl Carbene. Photoelectron spectra of various carbene radical anions have been reported in the literature. ${ }^{40,84,85}$ Comparison of these spectra with the spectrum of the AC radical anion casts some light on the chemical physics of the photodetachment events. For triatomic carbene systems with halogen substituents, energetic relations of the lowest singlet and triplet states have been systematically investigated. ${ }^{84}$ The photoelectron spectra of the halocarbene radical anions exhibit extensive vibrational progressions (both bending and stretching modes), especially in the triplet states of the corresponding carbenes. In the case of AC, the adiabatic potential energy surface of the radical anion is under the strong influence of the nonadiabatic interaction between the ${ }^{2} \mathrm{~A}^{\prime}$ and ${ }^{2} \mathrm{~A}^{\prime \prime}$ states. As described in section 3.2, a number of vibrational modes, including the methyl torsion mode, are substantially activated upon photodetachment from the radical anion to the ${ }^{3} \mathrm{~A}^{\prime \prime}$ state of $\mathrm{AC}$, leading to the congestion of the spectral transitions. As a result, the AC spectrum appears broad and structureless in the present measurements.

The electronic structure of AC may be of interest in regard to the mechanisms of the Wolff rearrangement reactions. ${ }^{86}$ Conversion of singlet $\mathrm{AC}$ to methylketene has been discussed in a neutralization - reionization mass spectroscopic study of the AC radical anion. ${ }^{35}$ The simplest carbene that undergoes such a rearrangement is formylcarbene. Computational studies have suggested that the electronic ground state of formylcarbene is a triplet state. ${ }^{87,88}$ Since the methyl substitution is not expected to alter the electronic structure dramatically, the ground state of $\mathrm{AC}$ most likely has the same spin multiplicity. This notion is supported by agreement between the results of the DFT calculations and the observations made in the photoelectron spectroscopic measurements, as described in section 3.2. It should be mentioned that ESR studies ${ }^{89}$ have revealed that carbonylcarbenes with simple substitution groups have triplet ground states, and both syn and anti conformations of the triplet states have been observed.

The photoelectron spectrum measured in the present study does not offer a positive sign of a low-lying singlet state of AC. According to the electronic structure calculations reported in the literature, ${ }^{88}$ the lowest singlet state of formylcarbene lies $<1 \mathrm{eV}$ above the triplet ground state. In particular, Kim and Schaefer ${ }^{90}$ predicted the singlet-triplet energy separation of carbohydroxycarbene to be $\sim 0.3 \mathrm{eV}$. Scott et al. demonstrated that the singlet potential energy surface is quite flat along the coordinate associated with transformation between formylcarbene and oxirene. $^{91}$ If the same situation applies to AC, detachment to the singlet state may only yield a broad photoelectron profile. It is possible that a portion of the photoelectron spectrum of the $\mathrm{AC}$ radical anion shown in Figure $7 \mathrm{~b}$ also accounts for detachment to the singlet state of AC.

4.3. Vibronic Structure of the 1-Methylvinoxy Radical. The photoelectron spectrum of the 1-MVO ion measured in the present study is in good agreement with the photoelectron imaging spectrum reported in the literature. ${ }^{70}$ This imaging spectrum has a much higher resolution, and it reveals the level structure of the methyl torsional mode in $\tilde{\mathrm{X}}^{2} \mathrm{~A}^{\prime \prime} 1$-MVO radical. The appearance of the extensive vibrational progression for the torsion mode reflects drastic change in the torsion potential energy surface from the 1-MVO ion to $\tilde{\mathrm{X}}^{2} \mathrm{~A}^{\prime \prime} 1$-MVO radical. These torsion levels are not resolved in the present measurements; instead, they broaden the photoelectron peaks significantly. Peak A in Figure 9a, which represents the vibrational ground level (save the torsion mode) of $\tilde{\mathrm{X}}^{2} \mathrm{~A}^{\prime \prime} 1$-MVO radical, has a fwhm of $17 \mathrm{meV}$. This line width is in accord with the finding in the imaging study ${ }^{70}$ that the vibronic transitions are split mainly by $\sim 5 \mathrm{meV}$ because of the methyl torsional levels. On the other hand, peak A in Figure 10a, which represents the vibrational ground level of $\tilde{\mathrm{A}}^{2} \mathrm{~A}^{\prime} 1$-MVO radical, has a fwhm of $11 \mathrm{meV}$. The torsional potential energy surface of $\tilde{\mathrm{A}}^{2} \mathrm{~A}^{\prime} 1-\mathrm{MVO}$ radical is quite similar to that of the 1-MVO ion (see Tables S8 and S9 in the Supporting Information), and the torsion mode is expected to be quite silent in the spectrum.

The DFT calculations find a potential minimum of $\tilde{\mathrm{X}}{ }^{1} \mathrm{~A}^{\prime}$ 1-MVO ion at a staggered conformation (Table S8 in the Supporting Information). The situation is the opposite of the ground state of acetone or acetaldehyde where the eclipsed conformation is lower in energy than the staggered one. ${ }^{92}$ There is a notable difference in the molecular structure between the 1-MVO ion and acetone. Deprotonation of acetone delocalizes 
the $\pi$ electrons in the MVO ion such that the highest occupied $\pi$ $\mathrm{MO}$ possesses a node between the $\mathrm{C}$ and $\mathrm{O}$ atoms (see Figure $\mathrm{S} 1$ in the Supporting Information). The DFT calculations predict the CO bond length in the 1-MVO ion to be $1.2723 \AA$ (Table S8 in the Supporting Information), much longer than that calculated for acetone, $1.2117 \AA \AA^{93}$ On the other hand, the CC bond length (that involves the methylene $\mathrm{C}$ atom) in the 1-MVO ion is calculated to be $1.3861 \AA$, much shorter than the corresponding bond length in acetone, $1.5171 \AA^{93}$ These results of the calculations indicate that the $\mathrm{CC}$ bond acquires a significant double-bond character in the 1-MVO ion while the CO bond assumes a single-bond character. In other words, the methyl group takes an eclipsed conformation with respect to the double bond in both acetone and 1-MVO ion. This trend of the conformation of the methyl group attached to the conjugated system has been discussed in the literature, ${ }^{94}$ and insightful analysis of methyl torsional energy has been presented. ${ }^{95}$

Photodetachment from the $\pi \mathrm{MO}$ of the 1-MVO ion shortens the $\mathrm{CO}$ bond and lengthens the $\mathrm{CC}$ bond for $\tilde{\mathrm{X}}^{2} \mathrm{~A}^{\prime \prime} 1-\mathrm{MVO}$ radical (Table S8 in the Supporting Information) such that the extent of conjugation is comparable between the $\mathrm{CO}$ and $\mathrm{CC}$ bonds. As a result, the eclipsed form is slightly more stable than the staggered one, but the potential energy curve along the methyl torsional coordinate is quite flat (Table S8 in the Supporting Information). ${ }^{70,96}$ The opposite geometry shifts take place in photodetachment from the $\sigma \mathrm{MO}$ of the 1-MVO ion (see Figure $\mathrm{S} 1$ and Table S8 in the Supporting Information), and the staggered form remains the most stable for $\tilde{\mathrm{A}}^{2} \mathrm{~A}^{\prime} 1$ 1-MVO radical.

The vibronic structure of $\tilde{\mathrm{X}}^{2} \mathrm{~A}^{\prime \prime} 1$-MVO radical has been well analyzed and compared with that of the unsubstituted vinoxy (VO) radical $^{97}$ in the previous photoelectron imaging study. ${ }^{70}$ As for $\widetilde{\mathrm{A}}{ }^{2} \mathrm{~A}^{\prime}$ 1-MVO radical, the present study reveals a weak vibronic peak that has not been identified in the previous study. This peak (peak E in Figure 10a) corresponds to the fundamental level of the $v_{7}$ mode $\left(\mathrm{CH}_{2}\right.$ scissor $)$. The simulated spectrum (Figure 10b) clearly reproduces this peak, which makes the assignment definitive. It should be noted that the photoelectron spectrum of the $\mathrm{VO}$ ion also exhibits a weak peak for the fundamental level of the $\mathrm{CH}_{2}$ scissor mode of $\tilde{\mathrm{A}}{ }^{2} \mathrm{~A}^{\prime} \mathrm{VO}$ radical. ${ }^{97}$ The fundamental vibrational frequency is found to be $1370 \pm 25 \mathrm{~cm}^{-1}$ for $\tilde{\mathrm{A}}^{2} \mathrm{~A}^{\prime} 1$-MVO radical, compared to $1404 \mathrm{~cm}^{-1}$ for $\tilde{\mathrm{A}}^{2} \mathrm{~A}^{\prime}$ VO radical. ${ }^{97}$

Further comparisons of the $\tilde{\mathrm{A}}^{2} \mathrm{~A}^{\prime}$ states of the 1-MVO and VO radicals clarify the effects of the methyl substitution. Besides the origin peak, the most intense peak in the photoelectron imaging spectrum for $\tilde{\mathrm{A}}{ }^{2} \mathrm{~A}^{\prime} \mathrm{VO}$ radical is located at $1533 \mathrm{~cm}^{-1}$, representing the fundamental level of the $\mathrm{CC}$ stretching mode. ${ }^{97}$ The corresponding CC stretching mode of $\tilde{\mathrm{A}}^{2} \mathrm{~A}^{\prime} 1$-MVO radical $\left(v_{5}\right)$ is also active in the photoelectron spectrum of the 1-MVO ion $^{98}$ with a fundamental vibrational frequency of $1565 \pm 25$ $\mathrm{cm}^{-1}$. The fundamental peak for the OCH (or $\mathrm{CCH}$ ) bending mode of $\tilde{\mathrm{A}}^{2} \mathrm{~A}^{\prime} \mathrm{VO}$ radical is also present in the photoelectron imaging spectrum ${ }^{97}$ with a vibrational frequency of $1218 \mathrm{~cm}^{-1}$. The corresponding mode in $\tilde{\mathrm{A}}^{2} \mathrm{~A}^{\prime} 1$-MVO radical $\left(v_{14}\right)$ is the inplane $\mathrm{CH}_{3}$ wagging mode, which is most active in the $\tilde{\mathrm{A}}$ state portion of the spectrum (Figure 10). The methyl substitution, however, shifts the frequency down to $380 \pm 15 \mathrm{~cm}^{-1}$. Peak $\mathrm{D}$ in Figure 10 is the fundamental level of the OCC asymmetric stretching mode of $\tilde{\mathrm{A}}^{2} \mathrm{~A}^{\prime} 1-\mathrm{MVO}$ radical $\left(v_{9}\right)$ at $1175 \pm 20 \mathrm{~cm}^{-1}$. Owing to the large difference in the force constant between the $\mathrm{CO}$ and $\mathrm{CH}$ stretch modes, these modes are not effectively coupled in the VO radical. ${ }^{97}$
Bowen and Continetti measured the angular distributions of the photoelectrons detached from the VO ion using a $354.8 \mathrm{~nm}$ $(3.494 \mathrm{eV})$ laser beam. ${ }^{99}$ Because the laser photon energy is close to that used in the present study and the eBE of the VO ion is also comparable to that of the 1-MVO ion, direct comparison of the $\beta$ values between the two studies is relevant. In the $\tilde{\mathrm{X}}^{2} \mathrm{~A}^{\prime \prime}$ portion of the spectrum, the $\beta$ value for the VO system is $-0.7 \pm 0.1,{ }^{99}$ which well matches that for the 1-MVO system, $-0.75 \pm 0.05$. On the other hand, the positive $\beta$ value, $+0.6 \pm 0.1$, for $\tilde{\mathrm{A}}^{2} \mathrm{~A}^{\prime} \mathrm{VO}$ radical $^{99}$ is in stark contrast to the negative one, $-0.60 \pm 0.05$, for $\tilde{\mathrm{A}}^{2} \mathrm{~A}^{\prime} 1$-MVO radical.

Figure $S 1$ in the Supporting Information shows that the $\pi \mathrm{MO}$ of the 1-MVO ion has only a minor contribution from the methyl group, and it does not much differ from that of the VO ion. Therefore, it is reasonable that the angular distributions of the photoelectrons detached from the $\pi \mathrm{MO}$ of the 1-MVO ion are very similar to those of the $\mathrm{VO}$ ion. The methyl substitution, however, introduces another significant node in the $\sigma \mathrm{MO}$ of the 1-MVO ion (see Figure S1 in the Supporting Information). The nature of the MO is significantly altered such that angular distributions of the photoelectrons detached from the $\sigma \mathrm{MO}$ of the 1-MVO ion are quite distinct from those of the VO ion. ${ }^{100}$

\section{CONCLUSIONS}

Photoelectron spectroscopic measurements have been carried out for the ion products of the reaction of $\mathrm{O}^{\bullet-}$ with acetone. The photoelectron spectrum of one of the product ions, the OXA radical anion, reveals the vibronic structure of the low-lying electronic states of OXA. B3LYP, CASSCF, and CASPT2 calculations facilitate the spectral analysis. The CASPT2 calculations predict the near degeneracy of the lowest singlet $\left({ }^{1} \mathrm{~A}_{1}\right)$ and triplet $\left({ }^{3} \mathrm{~B}_{2}\right)$ states of OXA. The presence of near-degenerate states in the spectrum is indeed inferred from the angular distributions of the photoelectrons. Spectral simulations of the ${ }^{1} \mathrm{~A}_{1}$ and ${ }^{3} \mathrm{~B}_{2}$ states have been carried out utilizing the results of the electronic structure calculations. The vibronic peaks observed in the spectrum have been positively identified through these simulations. The lowest electronic state of OXA is found to be singlet, and the EA of OXA is $1.940 \pm 0.010 \mathrm{eV}$. The triplet state lies higher in adiabatic energy than the ${ }^{1} \mathrm{~A}_{1}$ state by $55 \pm 2 \mathrm{meV}$. The spectrum for $\tilde{\mathrm{X}}^{1} \mathrm{~A}_{1}$ OXA exhibits a vibrational progression of the $\mathrm{CO}$ stretching mode, and the broad line widths of the observed peaks are most probably due to the transition state nature of the ${ }^{1} \mathrm{~A}_{1}$ state along the coordinate representing disrotatory motion of the methylene groups. This nuclear motion leads to formation of cyclopropanone. The spectrum for $\tilde{\mathrm{a}}^{3} \mathrm{~B}_{2} \mathrm{OXA}$ is characterized by a vibrational progression of the CCC bending mode. The $\tilde{b}^{3} \mathrm{~B}_{1}$ state of OXA has also been observed in the spectrum, with an electronic term energy of $0.883 \pm 0.012 \mathrm{eV}$. The CCC bending and $\mathrm{CO}$ stretching modes are active in the $\tilde{\mathrm{b}}^{3} \mathrm{~B}_{1}$ spectrum.

The other product ions studied here are the $\mathrm{AC}$ radical anion and the 1-MVO ion. An isotopologue of the AC radical anion has been isolated mass spectrometrically from the OXA radical anion in the reaction of $\mathrm{O}^{--}$with asymmetrically deuterated acetone. The photoelectron spectrum of the $\mathrm{AC}$ radical anion is broad and structureless. The broad band has been assigned to the $\tilde{\mathrm{X}}^{3} \mathrm{~A}^{\prime \prime}$ state of AC. The vibronic structures of the $\tilde{\mathrm{X}}^{2} \mathrm{~A}^{\prime \prime}$ and $\tilde{\mathrm{A}}^{2} \mathrm{~A}^{\prime}$ states of the 1-MVO radical are exposed in the photoelectron spectrum of the 1-MVO ion. The present findings are in good agreement with those of a recent high-resolution photoelectron imaging spectroscopic study, ${ }^{70}$ but the present work identifies new peaks 
representing the fundamental level of the $\mathrm{CH}_{2}$ scissoring mode of $\tilde{\mathrm{A}}^{2} \mathrm{~A}^{\prime} 1$-MVO radical and those of the OCC and CCC bending modes of $\tilde{\mathrm{X}}^{1} \mathrm{~A}^{\prime} 1$-MVO ion.

\section{ASSOCIATED CONTENT}

S Supporting Information. Results of quantum chemical calculations of the OXA, AC, and 1-MVO systems. This material is available free of charge via the Internet at http://pubs.acs.org.

\section{AUTHOR INFORMATION}

\section{Corresponding Author}

*E-mail: wcl@jila.colorado.edu.

\section{Present Addresses \\ ${ }^{\perp}$ Department of Chemical Engineering, Colorado School of Mines, Golden, CO, United States. \\ ${ }^{\nabla}$ Department of Chemistry, University of Alabama, Tuscaloosa, AL, United States. \\ OPacific Northwest National Laboratory, Richland, WA, United States.}

\section{ACKNOWLEDGMENT}

This work was funded by the U.S. National Science Foundation (NSF) and the U.S. Air Force Office of Scientific Research. W.T.B. thanks the Robert A. Welch Foundation for support through Grant B0027. Support for T.I. was provided by a grant from NSF (CHE-1012743) to Professor John F. Stanton of the University of Texas at Austin.

\section{REFERENCES}

(1) Longuet-Higgins, H. C. J. Chem. Phys. 1950, 18, 265-274. Dewar, M. J. S. The Molecular Orbital Theory of Organic Chemistry; McGraw-Hill: New York, 1969.

(2) Borden, W. T.; Davidson, E. R. Annu. Rev. Phys. Chem. 1979, 30, $125-153$.

(3) Borden, W. T. Effects of Electron Repulsion in Diradicals. In Diradicals; Borden, W. T., Ed.; Wiley: New York, 1982; pp 1-72.

(4) Borden, W. T.; Iwamura, H.; Berson, J. A. Acc. Chem. Res. 1994, 27, 109-116.

(5) Borden, W. T. Diradicals. In Encyclopedia of Computational Chemistry; Schleyer, P. v. R., Ed.; Wiley: Chichester, U.K., 1998; Vol. 1; pp 708-722.

(6) Weiss, F. Q. Rev. Chem. Soc. 1970, 24, 278-309 and references therein.

(7) Dowd, P. Acc. Chem. Res. 1972, 5, 242-248 and references therein.

(8) Dowd, P. J. Am. Chem. Soc. 1966, 88, 2587-2589. Dowd, P.; Gold, A.; Sachdev, K. J. Am. Chem. Soc. 1968, 90, 2715-2716. Cramer,

C. J. J. Chem. Soc., Perkin Trans. 2 1998, 1007-1013.

(9) Baseman, R. J.; Pratt, D. W.; Chow, M.; Dowd, P. J. Am. Chem. Soc. 1976, 98, 5726-5727.

(10) Borden, W. T.; Salem, L. J. Am. Chem. Soc. 1973, 95, 932-933.

(11) Borden, W. T.; Davidson, E. R. J. Am. Chem. Soc. 1977, 99, 4587-4594.

(12) Maier, G.; Reisenauer, H. P.; Lanz, K.; Tross, R; Jürgen, D.; Hess, B. A., Jr.; Schaad, L. J. Angew. Chem., Int. Ed. 1993, 32, 74-76. Maier, G.; Jürgen, D.; Tross, R.; Reisenauer, H. P.; Hess, B. A., Jr.; Schaad, L. J. Chem. Phys. 1994, 189, 383-399.

(13) Wenthold, P. G.; Hu, J.; Squires, R. R.; Lineberger, W. C. J. Am. Chem. Soc. 1996, 118, 475-476.

(14) Wenthold, P. G.; Hu, J.; Squires, R. R.; Lineberger, W. C. J. Am. Soc. Mass Spectrom. 1999, 10, 800-809.
(15) Dewar, M. J. S.; Wasson, J. S. J. Am. Chem. Soc. 1971, 93, 30813083. Yarkony, D. R.; Schaefer, H. F., III. J. Am. Chem. Soc. 1974, 96, 3754-3758. Hehre, W. J.; Salem, L.; Willcott, M. R. J. Am. Chem. Soc. 1974, 96, 4328-4330. Feller, D.; Borden, W. T.; Davidson, E. R. J. Chem. Phys. 1981, 74, 2256-2259. Brabec, J.; Pittner, J. J. Phys. Chem. A 2006, 110, 11765-11769. Li, X. Z.; Paldus, J. J. Chem. Phys. 2008, 129, 174101.

(16) Davidson, E. R.; Borden, W. T. J. Chem. Phys. 1976, 64, 663666. Borden, W. T. J. Am. Chem. Soc. 1976, 98, 2695-2700.

(17) Feller, D.; Tanaka, K.; Davidson, E. R; Borden, W. T. J. Am. Chem. Soc. 1982, 104, 967-972.

(18) Ma, B. Y.; Schaefer, H. F., III. Chem. Phys. 1996, 207, 31-41. Slipchenko, L. V.; Krylov, A. I. J. Chem. Phys. 2002, 117, 4694-4708. Slipchenko, L. V.; Krylov, A. I. J. Chem. Phys. 2005, 123, 084107. Demel, O.; Shamasundar, K. R.; Kong, L.; Nooijen, M. J. Phys. Chem. A 2008, 112, 11895-11902. Casanova, D.; Slipchenko, L. V.; Krylov, A. I.; Head-Gordon, M. J. Chem. Phys. 2009, 130, 044103.

(19) Cramer, C. J.; Smith, B. A. J. Phys. Chem. 1996, 100, 9664-9670.

(20) Slipchenko, L. V.; Krylov, A. I. J. Chem. Phys. 2003, 118, 68746883.

(21) Hoffmann, R. J. Am. Chem. Soc. 1968, 90, 1475-1485.

(22) Turro, N. J. Acc. Chem. Res. 1969, 2, 25-32. Sclove, D. B.; Pazos, J. F.; Camp, R. L.; Greene, F. D. J. Am. Chem. Soc. 1970, 92, 7488. Cordes, M. H. J.; Berson, J. A. J. Am. Chem. Soc. 1992, 114, 1101011011. Sorensen, T. S.; Sun, F. J. Am. Chem. Soc. 1995, 117, 5592-5593. Cordes, M. H. J.; Berson, J. A. J. Am. Chem. Soc. 1996, 118, 6241-6251. Sorensen, T. S.; Sun, F. Can. J. Chem. 1997, 75, 1030-1040. Sorensen, T. S.; Sun, F. J. Chem. Soc., Perkin Trans. 2 1998, 1053-1061.

(23) Lim, D. C.; Hrovat, D. A.; Borden, W. T.; Jorgensen, W. L. J. Am. Chem. Soc. 1994, 116, 3494-3499.

(24) Hess, B. A., Jr.; Eckart, U.; Fabian, J. J. Am. Chem. Soc. 1998, 120, $12310-12315$.

(25) Crandall, J. K.; Machleder, W. H. J. Am. Chem. Soc. 1968, 90, 7292-7296. Crandall, J. K.; Machleder, W. H.; Thomas, M. J. J. Am. Chem. Soc. 1968, 90, 7346-7347. Crandall, J. K.; Machleder, W. H. J. Am. Chem. Soc. 1968, 90, 7347-7349. Camp, R. L.; Greene, F. D. J. Am. Chem. Soc. 1968, 90, 7349. Chan, T. H.; Ong, B. S. J. Org. Chem. 1978, 43, 2994-3001. Ortiz, J. V. J. Org. Chem. 1983, 48, 47444749.

(26) Burr, J. G., Jr.; Dewar, M. J. S. J. Chem. Soc. 1954, 1201-1203. Wasserman, H. H.; Clark, G. M.; Turley, P. C. Top. Curr. Chem. 1974, 47, 73-156. Chenier, P. J. J. Chem. Educ. 1978, 55, 286-291.Hunter, D. H.; Stothers, J. B.; Warnhoff, E. W. Rearrangements in Carbanions. In Rearrangements in Ground and Excited States; de Mayo, P., Ed.; Academic Press: New York, 1980; Vol. 1, pp 391-470. Baretta, A.; Waegell, B. A Survey of Favorskii Rearrangement Mechanisms: Influence of the Nature and Strain of the Skeleton. In Reactive Intermediates; Abramovitch, R. A., Ed.; Plenum Press: New York, 1982; Vol. 2, pp 527585. Hamblin, G. D.; Jimenez, R. P.; Sorensen, T. S. J. Org. Chem. 2007, 72, 8033-8045.

(27) Hoffmann, H. M. R. Angew. Chem., Int. Ed. 1973, 12, 819-835. Schuster, D. I. Acc. Chem. Res. 1978, 11, 65-73. Noyori, R. Acc. Chem. Res. 1979, 12, 61-66. Schaffner, K.; Demuth, M. Photochemical Rearrangements of Conjugated Cyclic Dienones. In Rearrangements in Ground and Excited States; de Mayo, P., Ed.; Academic Press: New York, 1980; Vol. 3, pp 281-348. Noyori, R.; Hayakawa, Y. Org. React. 1983, 29, 163-344. Hoffmann, H. M. R. Angew. Chem., Int. Ed. 1984, 23, 119. Mann, J. Tetrahedron 1986, 42, 4611-4659. Schultz, A. G. Photorearrangement Reactions of Cross-Conjugated Cyclohexadienones. In CRC Handbook of Organic Photochemistry and Photobiology; Horspool, W. M., Song, P.-S., Eds.; CRC Press: Boca Raton, 1995; pp 685-700. Schultz, A. G. Cyclohexadienone Photochemistry: Trapping Reactions. In CRC Handbook of Organic Photochemistry and Photobiology; Horspool, W. M., Song, P.-S., Eds.; CRC Press: Boca Raton, 1995; pp 716-727.

(28) Osamura, Y.; Borden, W. T.; Morokuma, K. J. Am. Chem. Soc. 1984, 106, 5112-5115.

(29) Coolidge, M. B.; Yamashita, K.; Morokuma, K.; Borden, W. T. J. Am. Chem. Soc. 1990, 112, 1751-1754. 
(30) Hrovat, D. A.; Murcko, M. A.; Lahti, P. M.; Borden, W. T. J. Chem. Soc., Perkin Trans. 2 1998, 1037-1044.

(31) Borden, W. T. Qualitative and Quantitative Predictions and Measurements of Singlet-Triplet Splittings in Non-Kekulé Hydrocarbon Diradicals and Heteroatom Derivatives. In Magnetic Properties of Organic Materials; Lahti, P. M., Ed.; Marcel Dekker: New York, 1999; pp $61-102$.

(32) Ichino, T.; Villano, S. M.; Gianola, A. J.; Goebbert, D. J.; Velarde, L.; Sanov, A.; Blanksby, S. J.; Zhou, X.; Hrovat, D. A.; Borden, W. T.; Lineberger, W. C. Angew. Chem., Int. Ed. 2009, 48, 8509-8511.

(33) Mozhayskiy, V.; Goebbert, D. J.; Velarde, L.; Sanov, A.; Krylov, A. I. J. Phys. Chem. A 2010, 114, 6935-6943.

(34) Wenthold, P. G.; Hu, J.; Squires, R. R. J. Am. Chem. Soc. 1994, 116, 6961-6962.

(35) Schalley, C. A.; Blanksby, S.; Harvey, J. N.; Schröder, D.; Zummack, W.; Bowie, J. H.; Schwarz, H. Eur. J. Org. Chem. 1998, 987-1009.

(36) Harrison, A. G.; Jennings, K. R. J. Chem. Soc., Faraday Trans. 1 1976, 72, 1601-1608. Lee, J.; Grabowski, J. J. Chem. Rev. 1992, 92, 1611-1647. Lin, M. X.; Grabowski, J. J. Int. J. Mass Spectrom. 2004, 237, $149-165$.

(37) Dawson, J. H. J.; Noest, A. J.; Nibbering, N. M. M. Int. J. Mass Spectrom. Ion Phys. 1979, 30, 189-191.

(38) The previous studies (refs 36 and 37) have suggested that the vibrationally activated $\mathrm{AC}$ radical anion also fragments to $\mathrm{HCCO}^{-}$and the methyl radical either as a direct consequence of the reaction of $\mathrm{O}^{\bullet-}$ with acetone or following collisional activation. The present study clearly indicates that some $\mathrm{AC}$ radical anions are intact in the flowing afterglow ion source as well as in the pulsed ion source employed. See also ref 35.

(39) There are other reaction paths besides reactions $1-3$. See refs 36 and 37.

(40) Leopold, D. G.; Murray, K. K.; Stevens Miller, A. E.; Lineberger, W. C. J. Chem. Phys. 1985, 83, 4849-4865.

(41) Ervin, K. M.; Ho, J.; Lineberger, W. C. J. Chem. Phys. 1989, 91, 5974-5992.

(42) Ervin, K. M.; Lineberger, W. C. Photoelectron Spectroscopy of Molecular Anions. In Advances in Gas Phase Ion Chemistry; Adams, N. G., Babcock, L. M., Eds.; JAI Press: Greenwich, CT, 1992; Vol. 1, pp 121166.

(43) Neumark, D. M.; Lykke, K. R.; Andersen, T.; Lineberger, W. C. Phys. Rev. A 1985, 32, 1890-1892.

(44) Moore, C. E. Atomic Energy Levels. As Derived From the Analyses of Optical Spectra; NSRDS-NBS 35 (reprint of NBS Circular 467);

National Bureau of Standards: Washington, DC, 1971; Vol. 3.

(45) Cooper, J.; Zare, R. N. J. Chem. Phys. 1968, 48, 942-943.

(46) Velarde, L.; Habteyes, T.; Sanov, A. J. Chem. Phys. 2006, 125, 114303.

(47) Eppink, A. T. J. B.; Parker, D. H. Rev. Sci. Instrum. 1997, 68, 3477-3484.

(48) Chandler, D. W.; Houston, P. L. J. Chem. Phys. 1987, 87, 14451447.

(49) Dribinski, V.; Ossadtchi, A.; Mandelshtam, V. A.; Reisler, H. Rev. Sci. Instrum. 2002, 73, 2634-2642.

(50) Becke, A. D. J. Chem. Phys. 1993, 98, 5648-5652. Lee, C. T.; Yang, W. T.; Parr, R. G. Phys. Rev. B 1988, 37, 785-789.

(51) Roos, B. O. Int. J. Quantum Chem. 1980, S14, 175-189. Roos, B. O. Adv. Chem. Phys. 1987, 69, 399-445.

(52) Borden, W. T.; Davidson, E. R. Acc. Chem. Res. 1996, 29, 67-75.

(53) Andersson, K.; Malmqvist, P.-Å.; Roos, B. O.; Sadlej, A. J.; Wolinski, K. J. Phys. Chem. 1990, 94, 5483-5488. Andersson, K.; Malmqvist, P.-Å.; Roos, B. O. J. Chem. Phys. 1992, 96, 1218-1226.

(54) Krishnan, R.; Binkley, J. S.; Seeger, R.; Pople, J. A. J. Chem. Phys. 1980, 72, 650-654.

(55) Dunning, T. H., Jr. J. Chem. Phys. 1989, 90, 1007-1023.

(56) Kendall, R. A.; Dunning, T. H., Jr.; Harrison, R. J. J. Chem. Phys. 1992, 96, 6796-6806.

(57) Frisch, M. J.; Trucks, G. W.; Schlegel, H. B.; Scuseria, G. E.; Robb, M. A.; Cheeseman, J. R.; Montgomery, J. A., Jr.; Vreven, T.;
Kudin, K. N.; Burant, J. C.; Millam, J. M.; Iyengar, S. S.; Tomasi, J.; Barone, V.; Mennucci, B.; Cossi, M.; Scalmani, G.; Rega, N.; Petersson, G. A.; Nakatsuji, H.; Hada, M.; Ehara, M.; Toyota, K.; Fukuda, R.; Hasegawa, J.; Ishida, M.; Nakajima, T.; Honda, Y.; Kitao, O.; Nakai, H.; Klene, M.; Li, X.; Knox, J. E.; Hratchian, H. P.; Cross, J. B.; Adamo, C.; Jaramillo, J.; Gomperts, R.; Stratmann, R. E.; Yazyev, O.; Austin, A. J.; Cammi, R.; Pomelli, C.; Ochterski, J. W.; Ayala, P. Y.; Morokuma, K.; Voth, G. A.; Salvador, P.; Dannenberg, J. J.; Zakrzewski, V. G.; Dapprich, S.; Daniels, A. D.; Strain, M. C.; Farkas, O.; Malick, D. K.; Rabuck, A. D.; Raghavachari, K.; Foresman, J. B.; Ortiz, J. V.; Cui, Q.; Baboul, A. G.; Clifford, S.; Cioslowski, J.; Stefanov, B. B.; Liu, G.; Liashenko, A.; Piskorz, P.; Komaromi, I.; Martin, R. L.; Fox, D. J.; Keith, T.; Al-Laham, M. A.; Peng, C. Y.; Nanayakkara, A.; Challacombe, M.; Gill, P. M. W.; Johnson, B.; Chen, W.; Wong, M. W.; Gonzalez, C.; Pople, J. A. Gaussian 03, revision B.05; Gaussian, Inc.: Pittsburgh, PA, 2003.

(58) Karlström, G.; Lindh, R.; Malmqvist, P.-Å.; Roos, B. O.; Ryde, U.; Veryazov, V.; Widmark, P.-O.; Cossi, M.; Schimmelpfennig, B.; Neogrady, P.; Seijo, L. Comput. Mater. Sci. 2003, 28, 222-239.

(59) The zero-point vibrational energy has been taken into account under the harmonic approximation.

(60) Ervin, K. M.; Ramond, T. M.; Davico, G. E.; Schwartz, R. L.; Casey, S. M.; Lineberger, W. C. J. Phys. Chem. A 2001, 105, 1082210831.Ervin, K. M. PESCAL, Fortran Program; University of Nevada, Reno: Reno, 2003.

(61) The harmonic vibrational frequencies from the (4/4)CASSCF/ cc-pVTZ calculations were used to evaluate the zero-point vibrational energy.

(62) The ${ }^{1} A_{1}$ simulation took account of only the totally symmetric modes. The harmonic frequencies were scaled by 0.9 for the simulation.

(63) Analogous to the spectra in Figure $2 b$, photoelectron contributions from 1-MVO ions are already subtracted in Figure 4a. In contrast to the room temperature spectra shown in Figure 3, the spectrum of ions generated in the cooled flow tube shown in Figure 4a does not indicate a significant presence of AC radical anions in the $m / e 56$ ion beam. The relative abundance of ion products of reactions $1-3$ depends on the specific flow tube conditions (e.g., neutral reactant concentration, impurity concentration, reaction time). See also ref 36 .

(64) Aside from the $\mathrm{CO}$ stretching mode, the ${ }^{1} \mathrm{~A}_{1}$ simulation also displays weak peaks associated mainly with the CCC symmetric stretching mode $\left(v_{6}\right)$. These peaks are too weak to be clearly recognized in the observed spectrum.

(65) In the preliminary publication (ref 32), the EA of OXA was reported to be $1.942 \pm 0.010 \mathrm{eV}$. The energy scale has been more accurately calibrated since then, and the present value of $1.940 \pm 0.010$ $\mathrm{eV}$ replaces the old one.

(66) The geometry of cyclopropanone has been determined in a microwave study. Pochan, J. M.; Baldwin, J. E.; Flygare, W. H. J. Am. Chem. Soc. 1969, 91, 1896-1898.

(67) Öpik, U.; Pryce, M. H. L. Proc. R. Soc. London, Ser. A 1957, 238, 425-447. Pearson, R. G. J. Am. Chem. Soc. 1969, 91, 4947-4955.

(68) Köppel, H.; Domcke, W.; Cederbaum, L. S. Adv. Chem. Phys. 1984, 57, 59-246.

(69) Ellison, G. B.; Engelking, P. C.; Lineberger, W. C. J. Phys. Chem. 1982, 86, 4873-4878. Alconcel, L. S.; Deyerl, H.-J.; Continetti, R. E. J. Am. Chem. Soc. 2001, 123, 12675-12681.

(70) Yacovitch, T. I.; Garand, E.; Neumark, D. M. J. Phys. Chem. A 2010, 114, 11091-11099.

(71) For the simulation of the $\tilde{\mathrm{X}} 2 \mathrm{~A}^{\prime \prime}$ state of the 1-MVO radical, the results of the DFT calculations for the staggered conformation of the radical were used, even though it is a transition state. Apart from the methyl torsional mode, the calculated harmonic vibrational frequencies are very similar between the staggered (transition state) and eclipsed (minimum) conformers; see Table S9 in the Supporting Information.

(72) Davidson, E. R.; Borden, W. T. J. Am. Chem. Soc. 1977, 99, 2053-2060.

(73) Borden, W. T.; Davidson, E. R. Acc. Chem. Res. 1981, 14, 69-76.

(74) Englman, R. The Jahn-Teller Effect in Molecules and Crystals; Wiley: London, 1972. 
(75) That is, a transition state with respect to the pseudorotation. Technically, it is a second-order saddle point because the ${ }^{1} \mathrm{~B}_{2}$ state is also a maximum with respect to an $\mathrm{a}_{2}$ coordinate which represents torsion of the unique methylene group.

(76) This second-order effect could also take place through quadratic Jahn-Teller coupling within the ${ }^{1} \mathrm{E}^{\prime}$ state. See ref 74 .

(77) Neumark, D. M. Acc. Chem. Res. 1993, 26, 33-39. Wenthold, P. G.; Lineberger, W. C. Acc. Chem. Res. 1999, 32, 597-604. See also ref 35 for a discussion on the ring closure of OXA to form cyclopropanone in collisional neutralization of the OXA radical anion.

(78) B3LYP $/ 6-311++G(d, p)$ calculations suggest that the first excited state, ${ }^{2} \mathrm{~B}_{1}$, of the OXA radical anion is located higher in adiabatic energy than the ${ }^{2} \mathrm{~A}_{2}$ state by $1.241 \mathrm{eV}$.

(79) In contrast to the ${ }^{1} \mathrm{E}^{\prime}$ state of TMM, the equilibrium geometries of the ${ }^{2} \mathrm{~A}_{2}$ and ${ }^{2} \mathrm{~B}_{1}$ states of the TMM radical anion reported in ref 14 suggest that the linear Jahn-Teller interaction along the $\mathrm{e}^{\prime}$ bending coordinate is quite effective in the ${ }^{2} \mathrm{E}^{\prime \prime}$ state of the TMM radical anion. In this context, it is worthwhile to comment that the sequence band observed in the photoelectron spectrum for $\tilde{\mathrm{X}}^{3} \mathrm{~A}_{2}{ }^{\prime} \mathrm{TMM}$ (ref 14) may be associated with transitions from a $J= \pm 3 / 2$ level of the TMM radical anion. Here, $J$ stands for the linear Jahn-Teller angular momentum quantum number (see Longuet-Higgins, H. C. Adv. Spectrosc. 1961, 2, 429). The vibrational energy of the $J= \pm 3 / 2$ level could possibly be much lower than the fundamental vibrational frequency of the CCC bending mode of $\tilde{\mathrm{X}}^{3} \mathrm{~A}_{2}^{\prime} \mathrm{TMM}, 425 \pm 10 \mathrm{~cm}^{-1}$ (ref 14) owing to the nonadiabatic interaction. Then, significant thermal population of the $J= \pm 3 / 2$ level is quite likely for the TMM radical anion produced in the flowing afterglow ion source. On the other hand, in the absence of linear Jahn-Teller effects, the fundamental level of the asymmetric inplane bending mode may not be very low in the ${ }^{2} \mathrm{~A}_{2}$ state of the OXA radical anion. According to DFT calculations, the corresponding $b_{2}$ mode has a harmonic frequency of $493 \mathrm{~cm}^{-1}$ under the adiabatic approximation; see Table S1 in the Supporting Information. No sequence band is noticeable in the photoelectron spectrum of the OXA radical anion.

(80) This is so as long as the nuclear configuration does not allow mixing with the ${ }^{2} \mathrm{~B}_{1}$ state. See Ichino, T.; Gauss, J.; Stanton, J. F. J. Chem. Phys. 2009, 130, 174105.

(81) Dellepiane, G.; Overend, J. Spectrochim. Acta 1966, 22, 593614.

(82) As commented earlier in section 4.1, the $\tilde{b}^{1} \mathrm{~A}_{1}$ TMM spectrum in ref 14 exhibits a broad peak which may represent the fundamental level of the CC stretching mode. If this is the case, then it may indicate that, at this nuclear geometry, the ${ }^{1} \mathrm{~A}_{1}$ state has a negative potential energy curvature along the ring-closing coordinate. In this sense, the $\mathrm{CC}$ stretching coordinate plays a role equivalent to that the $\mathrm{CO}$ stretching coordinate does in their corresponding singlet potential energy surfaces.

(83) At the $C_{2 v}$ equilibrium geometry of the ${ }^{1} \mathrm{~B}_{2}$ state, the ${ }^{1} \mathrm{~A}_{1}$ potential energy is higher than the ${ }^{1} B_{2}$ energy.

(84) Murray, K. K.; Leopold, D. G.; Miller, T. M.; Lineberger, W. C. J. Chem. Phys. 1988, 89, 5442-5453. Gilles, M. K.; Ervin, K. M.; Ho, J.; Lineberger, W. C. J. Phys. Chem. 1992, 96, 1130-1141. Schwartz, R. L.; Davico, G. E.; Ramond, T. M.; Lineberger, W. C. J. Phys. Chem. A 1999, 103, 8213-8221. Wren, S. W.; Vogelhuber, K. M.; Ervin, K. M.; Lineberger, W. C. Phys. Chem. Chem. Phys. 2009, 11, 4745-4753.

(85) Velarde, L.; Habteyes, T.; Glass, R. S.; Sanov, A. J. Phys. Chem. A 2009, 113, 3528-3534. Goebbert, D. J.; Pichugin, K.; Khuseynov, D.; Wenthold, P. G.; Sanov, A. J. Chem. Phys. 2010, 132, 224301.

(86) Meier, H.; Zeller, K.-P. Angew. Chem., Int. Ed. 1975, 14, $32-43$. Kirmse, W. Eur. J. Org. Chem. 2002, 2193-2256. Tidwell, T. T. Ketenes II; Wiley: Hoboken, 2006.

(87) Baird, N. C.; Taylor, K. F. J. Am. Chem. Soc. 1978, 100, 13331338.

(88) Tanaka, K.; Yoshimine, M. J. Am. Chem. Soc. 1980, 102, 76557662. Gosavi, R. K.; Torres, M.; Strausz, O. P. Can. J. Chem. 1991, 69, $1630-1635$.

(89) Hutton, R. S.; Roth, H. D. J. Am. Chem. Soc. 1978, 100, 43244325. Murai, H.; Ribo, J.; Torres, M.; Strausz, O. P. J. Am. Chem. Soc.
1981, 103, 6422-6426. Torres, M.; Safarik, I.; Murai, H.; Strausz, O. P. Rev. Chem. Intermed. 1986, 7, 243-270.

(90) Kim, K. S.; Schaefer, H. F., III. J. Am. Chem. Soc. 1980, 102, $5389-5390$.

(91) Scott, A. P.; Nobes, R. H.; Schaefer, H. F., III; Radom, L. J. Am. Chem. Soc. 1994, 116, 10159-10164.

(92) Kilb, R. W.; Lin, C. C.; Wilson, E. B., Jr. J. Chem. Phys. 1957, 26, 1695-1703. Swalen, J. D.; Costain, C. C. J. Chem. Phys. 1959, 31, 15621574. Peter, R.; Dreizler, H. Z. Naturforsch. 1965, A20, 301-312.

(93) The equilibrium geometry of acetone obtained with B3LYP/6$311++G(d, p)$ calculations compares well with those determined from experiments. The DFT geometric parameters are $\mathrm{CO}=1.2117 \AA, \mathrm{CC}=$ $1.5171 \AA$, and $\mathrm{CCC}=116.57^{\circ}$. Microwave spectroscopic measurements give the following values: $\mathrm{CO}=1.222 \pm 0.003 \AA, C C=1.507 \pm 0.003 \AA$, and CCC $=117.20 \pm 0.33^{\circ}$. See Nelson, R; Pierce, L. J. Mol. Spectrosc. $1965,18,344-352$. Electron diffraction measurements give the following values: $\mathrm{CO}=1.2110 \pm 0.0041 \AA$ and $\mathrm{CC}=1.5167 \pm 0.0048 \AA$. See Kato, C.; Konaka, S.; Iijima, T.; Kimura, M. Bull. Chem. Soc. Jpn. 1969, 42, 2148-2158. Analysis of experimental data has also been performed to give the following zero-point average structure: $\mathrm{CO}=1.210 \pm 0.004$ $\AA$. CC $=1.517 \pm 0.003 \AA$, and CCC $=116.00 \pm 0.25^{\circ}$. See Iijima, T. Bull. Chem. Soc. Jpn. 1972, 45, 3526-3530.

(94) Hehre, W. J.; Pople, J. A.; Devaquet, A. J. P. J. Am. Chem. Soc. 1976, 98, 664-668. Dorigo, A. E.; Pratt, D. W.; Houk, K. N. J. Am. Chem. Soc. 1987, 109, 6591-6600.

(95) Goodman, L.; Kundu, T.; Leszczynski, J. J. Phys. Chem. 1996, 100, 2770-2783. Guo, D.; Goodman, L. J. Phys. Chem. 1996, 100, 12540-12545. Goodman, L.; Pophristic, V.; Weinhold, F. Acc. Chem. Res. 1999, 32, 983-993.

(96) Williams, S.; Harding, L. B.; Stanton, J. F.; Weisshaar, J. C. J. Phys. Chem. A 2000, 104, 10131-10138.

(97) Yacovitch, T. I.; Garand, E.; Neumark, D. M. J. Chem. Phys. 2009, 130, 244309.

(98) Peak F in Figure 10a also has a significant contribution from the transition to the combination level of the $v_{9}$ and $v_{14}$ modes, as suggested in $\operatorname{ref} 70$.

(99) Bowen, M. S.; Continetti, R. E. J. Phys. Chem. A 2004, 108, $7827-7831$

(100) It should be noted that the $\beta$ values of the photoelectrons detached in the threshold region are positive for $\tilde{\mathrm{A}}^{2} \mathrm{~A}^{\prime} 1$-MVO radical. See ref 70 . 